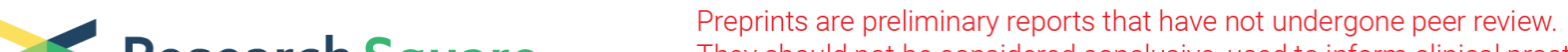 $\begin{array}{ll}\text { Research Square } & \text { They should not be considered conclusive, used to inform clinical practice, } \\ \text { or referenced by the media as validated information. }\end{array}$
}

\section{The Associations between Inflammatory Bowel Disease and a Range of Other DiseasesđUmbrella Review of Systematic Reviews and Meta-analyses}

\section{Liqun Li}

Guangxi Traditional Chinese Medical University Affiliated First Hospital

\section{Qianli Cen}

Youjiang Medical University for Nationalities

\section{Lijian Liu}

Guangxi Traditional Chinese Medical University Affiliated First Hospital

\section{Jinxiu Wei}

Guangxi Traditional Chinese Medical University Affiliated First Hospital Jinjing Tan

Guangxi Traditional Chinese Medical University Affiliated First Hospital Jianfeng Li

Guangxi Traditional Chinese Medical University Affiliated First Hospital

\section{Yalu Chen}

Guangxi Traditional Chinese Medical University Affiliated First Hospital

\section{Yuanyuan Liu}

Guangxi Traditional Chinese Medical University Affiliated First Hospital

\section{Guangwen Chen}

Guangxi Traditional Chinese Medical University Affiliated First Hospital

Sheng Xie ( $D$ xiesheng2018tougao@163.com)

Guangxi Traditional Chinese Medical University Affiliated First Hospital https://orcid.org/0000-0003-42763068

\section{Research}

Keywords: inflammatory bowel disease, Crohn's disease, ulcerative colitis, umbrella review

Posted Date: April 8th, 2021

DOl: https://doi.org/10.21203/rs.3.rs-401434/v1

License: (a) (i) This work is licensed under a Creative Commons Attribution 4.0 International License. Read Full License 


\section{Abstract \\ Background}

Multiple meta-analyses have reported inflammatory bowel diseases (IBD) are associated with an increased risk of diverse diseases, but the evidence quality remains unclear.

\section{Objectives}

We aimed to summarize and evaluate this existing evidence on the associations between IBD and a range of diseases a-crossed from meta-analyses.

\section{Methods}

PubMed, the Cochrane Library Database, Embase, Web of Science, CNKI Databases, Wanfang Databases and VIP Database were searched to obtain eligible literatures from inception to November 1, 2019. We appraised the methodological quality of the included meta-analyses using AMSTAR 2 tool, and evaluated the quality of evidence for each outcome using the GRADE approach.

\section{Results}

Nineteen articles covering associations between IBD and 28 types of health outcomes were included. The methodological quality of meta-analyses was rated moderate for $5.26 \%$, low for $21.05 \%$, and critically low for 73.68\%. Overall, summary effect estimates were significant in 26 meta-analyses. The evidence quality was rated high for $3.57 \%$, moderate for $21.43 \%$, low for $28.57 \%$, and very low for $46.43 \%$. Evidence quality was high for association between IBD and an increased periodontitis risk (OR = 4.55; 95\% $\mathrm{Cl}, 3.00-6.19)$. Evidence quality was moderate for associations between IBD and an increased thyroid cancer risk $(\mathrm{OR}=1.75 ; 95 \% \mathrm{Cl}$, 1.48-2.07), myocardial infarction incidence ( $R R=1.12 ; 95 \% \mathrm{Cl}, 1.05-1.21)$, preterm birth incidence $(\mathrm{OR}=1.85$; $95 \% \mathrm{Cl}, 1.67-2.05)$, stillbirth incidence $(\mathrm{OR}=1.57 ; 95 \% \mathrm{Cl}, 1.03-2.38)$, gallstone disease prevalence $(\mathrm{OR}=1.72$; $95 \% \mathrm{Cl}, 1.40-2.12)$, and vitamin D deficiency prevalence $(\mathrm{OR}=1.64 ; 95 \% \mathrm{Cl}, 1.30-2.08)$.

\section{Conclusions}

Though, associations between IBD and diverse diseases have been extensively studied, few of the reported associations have robust support. Further well-designed studies are essential to determine whether IBD increases the risk of other diseases.

\section{Introduction}

Inflammatory bowel disease (IBD), including Crohn's disease (CD) and ulcerative colitis (UC), is a group of chronic immune-mediated idiopathic inflammatory diseases influenced by both genetic and environmental 
factors [1-3]. IBD is a global disease in the 21 st century, showing accelerating incidence [4-6]. More than 6.8 million people worldwide suffer from IBD, which imparts a massive economic burden on public health [7]. As a lifelong chronic relapsing disorder with an early onset, IBD is painful and debilitating. Chronic inflammation of IBD may lead to a variety of serious complications. Multiple meta-analyses have reported that patients with IBD are at increased risk for many diseases (e.g., extra-intestinal cancers [8], nonalcoholic fatty liver disease [9], cardiovascular diseases [10]), indicating that IBD may be a contributor to both mortality and morbidity rates in patients with these diseases. Simultaneously, the global burden of these diseases is growing rapidly [11-13]. Studying and clarifying associations of IBD and diverse diseases may be of great value in the diagnosis and treatment of these conditions. Therefore, it is necessary to summarize the associations between IBD and related diseases. However, to the best of our knowledge, no study has, to date, comprehensively summarized associations between IBD and various diseases.

In addition, although many meta-analyses have revealed associations between IBD and multiple diseases, the quality of the available evidence remains unclear. The observed associations between IBD and diverse diseases could be either causal or because of confounding factors. Design scheme defects, risk of bias, small sample size effects and inconsistencies between studies could result in a downgrade of the quality of evidence. Furthermore, some findings are contradictory $[14,15]$. Therefore, it is important to clarify the quality of evidence of these associations. However, no studies have been conducted yet to evaluate the quality of evidence in this regard; hence, critically apprising the body of evidence of associations between IBD and a range of diseases is needed. An umbrella review involves systematically searching, collecting and assessing the existing evidence derived from various systematic reviews and meta-analyses on any clinical health outcomes related to a particular involves [16]. An umbrella review can not only comprehensively summarize evidence of associations between IBD and diverse diseases, but can also clarify the quality of the evidence, providing clinicians with an overall picture of the subject under consideration.

This study aimed to perform an umbrella review to summarize the evidence of associations between IBD and diverse diseases derived from systematic reviews and meta-analyses, and to assess the quality of evidence of these associations.

\section{Methods And Methods}

Our study was registered in PROSPERO (https://www.crd.york.ac.uk/prospero/, CRD42020158433), the international prospectively registered platform for systematic reviews [17]. This umbrella review was reported according to the Meta-analyses of Observational Studies in Epidemiology (MOOSE) recommendations [18].

\section{Literature search}

PubMed, Embase, the Cochrane Library Database, Web of Science, CNKI database, Wanfang database, and VIP database were independently searched by two researchers (Lijian Liu, Jinxiu Wei) from their inception to November 1, 2019 for meta-analyses and/or systematic reviews of observational studies investigating associations between IBD and diverse diseases. The search strategy involved a combination of medical subject terms, words, and free text. The search strategies of deployed in the selected literature databases are shown in Appendix 1. The references of the eligible literature were also searched by hand. 


\section{Study selection}

We included only meta-analyses and/or systematic reviews with a meta-analysis of observational studies (e.g., cohort studies, case-control studies and cross-sectional studies) exploring associations between IBD and diverse diseases in humans. Eligible studies included the following aspects: (1) exposure: IBD; (2) comparator: non-IBD; (3) outcomes (s): risk/ incidence/ prevalence of diverse diseases. We included studies with specific data such as relative risk (RR), odds ratio (OR), standardized incidence ratio (SIR), standardized mortality ratio (SMR) and corresponding $95 \%$ confidence interval $(95 \% \mathrm{Cl})$. If there was more than one eligible outcome in a meta-analysis, we retrieved each of them separately. When more than one published metaanalysis studying the same association was identified, the one with the largest number of primary studies included was retained. If more than one published meta-analysis on the same association included the same number of primary studies, the one with the largest number of prospective studies or participants was included. If more than one published meta-analysis on the same association met both criteria, the one with more information available (e.g., subgroup analyses) was selected.

Meta-analyses that only contained information on cumulative risk were excluded. Studies were also excluded if not published in full form as peer-reviewed literature. We also excluded meta-analyses with incomplete or inconsistent data that had not been confirmed by the author.

Two reviewers (Liqun Li, Qianli Cen) screened all articles identified from the search independently. First, titles and abstracts of articles were screened. Second, full texts were scrutinized for applicability. Third, references of all eligible articles were hand-searched. Any disagreement between reviewers were resolved by discussion to reach a consensus and a third review (Sheng Xie) arbitrated all discrepancies.

\section{Data extraction}

For each eligible study, two reviewers (Liqun Li, Qianli Cen) independently extracted information on the name of the first author, year of publication, outcome(s), epidemiologic design and number of included studies, number of cases and controls (for case-control studies) or number of cases and participants (for cohort studies), the meta-analytic model used (fixed or random), and meta-analytic estimates and their corresponding $95 \%$ Cls. We also abstracted the results of heterogeneity, publication bias and subgroup analysis. All of the results were carefully checked by a third reviewer.

\section{Methodological quality assessment}

A Measurement Tool to Assess Systematic Reviews 2 (AMSTAR 2), a reliable and valid tool [19, 20], was used to assess the risk of methodological bias observed in each article by two investigators (Lijian Liu, Jinxiu Wei). The revised AMSTAR 2 was developed from AMSTAR and contains 16 checklists in total, including seven critical domains (items $2,4,7,9,11,13$ and 15) and nine noncritical items (items 1, 3, 5, 6, 8, 10, 12, 14 and 16). AMSTAR 2 does not generate an overall score, but rather provides three ("yes", "partial yes", and "no") responses to the satisfaction level of the checklists. The rating criteria of AMSTAR 2 were as follows: high quality was rated when no or one noncritical weakness was found; moderate quality was rated when more than one noncritical weakness was found; low quality was rated when one critical flaw with or without noncritical weaknesses was found; and critically low quality was rated when more than one critical flaw with 
or without noncritical weaknesses was found [19]. The results were checked by a third investigator (Jianfeng $\mathrm{Li}$ ) and discrepancies were resolved by discussion with the review group.

\section{Evidence quality assessment}

The Grading of Recommendations, Assessment, Development and Evaluation (GRADE) approach was employed to rate the quality of evidence across every outcome [21, 22]. From here, the evidence quality could be further downgraded by five factors (study limitations, inconsistency of results, indirectness of evidence, imprecision and potential publication bias), or upgraded by three factors (large magnitude of effect, dose response and confounders). When there was a serious or very serious defect for downgrading factors, the evidence quality was lowered by one or two level(s), respectively. When there was large effect (RR/OR of either $>2.0$ ) or very large effect (RR/OR of either > 5.0), the evidence quality was increased by one or two level(s), respectively. When there was evidence of a gradient dose response, the evidence quality was upgraded by one level. If there was evidence that the influence of all plausible confounding would reduce a demonstrated effect or suggest a spurious effect, the evidence quality was upgraded by one level. The primary evidence quality of observational studies was considered as "low"; the evidence quality was rated as "very low" by downgrading one level or more; the evidence quality was rated as "moderate" and "high "by upgrading one or two levels, respectively. Ultimately, the evidence quality of the outcomes was categorized as high, moderate, low or very Iow [21, 22]. The GRADE assessment was independently conducted by two reviewers (Jinjing Tan, Yalu Chen), and the results were checked by a third investigator (Yuanyuan Liu). Discordant decisions were resolved by a team researcher (Sheng Xie).

\section{Data synthesis}

If the included meta-analyses did not present the results of pooled meta-analysis (RRs, ORs, SMRs, or SIRs), I², Egger's test, or publication bias, we extracted the necessary data from primary studies to recalculate them as possible as we could. Publication bias was estimated by using Egger's test (significant at $p<0.10)[23]$. Cochrane $Q$ test (significant at $p<0.10$ ) and $I^{2}$ statistics were used to assess the heterogeneity [24]. For $\mathrm{I}^{2}$ statistics, a value of more than $50 \%$ was considered to indicate significant heterogeneity. A random-effects model was employed to calculate the relative summary risk estimates when significant heterogeneity was observed [25]. Otherwise, a fixed-effects model was used. All statistical analysis was conducted using Stata version 15.0 (IBM Corp., Armonk, NY, USA).

\section{Results}

\section{Description of the included meta-analyses}

A total of 9,310 records were found through an initial database review. After screening the titles and abstracts, 64 articles were kept as full-text articles for additional review. Ultimately, 19 articles covering associations between IBD and 28 types of health outcomes were included (Fig. 1). The included meta-analyses were published in English between 2014 and 2019. Various disease outcomes included cancers $(n=7)$ [26-31], cardiovascular and cerebrovascular diseases $(n=8)$ [32-35], obstetrical diseases $(n=4)$ [36], neuropsychiatric disease $(n=1)$ [38], otolaryngology and stomatology diseases $(n=2)[41,43]$ and others $(n=6)[37,39-40,42,44]$ (Table 1). A total of 249 individual study estimates were included among the 19 articles. Among the 249 
individual studies, 204 (81.93\%) were cohort studies, 36 (14.46\%) were case-control studies, and nine (3.61\%) were cross-sectional studies. Three to 23 studies estimates were pooled in per meta-analysis, while the median study estimate count was eight. The number of primary studies that pooled in $60.71 \%$ of meta-analyses was less than 10. Five meta-analyses did not provide the total number of participants [34, 44], while 13 metaanalyses did not provide the total number of cases [26, 33-36, 41, 43, 44]. Among the meta-analyses that indicated the number of cases or participants, the median number of participants was 352,977 (811$940,572,339)$, and the median number of cases was 4,984 (117-120,312). A total of 22 meta-analyses included more than 1,000 participants, 10 meta-analyses included more than 1,000 cases and two metaanalyses included less than 300 cases.

\section{Heterogeneity between studies and publication bias}

Table 1 shows the heterogeneity between studies. Eighteen meta-analyses (64.29\%) reported significant heterogeneity between studies with $p<0.10$ or $\mathrm{I}^{2}>50 \%$. There was moderate heterogeneity $\left(\mathrm{I}^{2}=50 \%-75 \%\right)$ in five (17.85\%) meta-analyses and high heterogeneity $\left(\mathrm{I}^{2}>75 \%\right)$ in eleven (39.28\%) meta-analyses. Two metaanalyses were reanalyzed because they did not present the results of publication bias [32, 41]. Only one metaanalysis indicated the existence of publication bias [36].

\section{Methodological quality of included meta-analyses}

The assessment results of the AMSTAR2 are shown in Supplemental Table 3 and Fig. 6. Seventeen (89.47\%) meta-analyses did not report explicit statements or protocols. Thirteen (68.42\%) meta-analyses did not use comprehensive literature search strategies. Thirteen (68.42\%) meta-analyses did not provide a list of exclude studies and justify the exclusions. Five (26.31\%) meta-analyses did not use a satisfactory technique for assessing the risk of bias in the primary studies. None of the meta-analyses reported the details of funding sources for the included studies. Overall, the methodological qualities of the included meta-analyses were rated as moderate for $5.26 \%(n=1)$, low for $21.05 \%(n=4)$, and critically low for $73.68 \%(n=14)$.

\section{Associations and quality of evidence between IBD and various diseases}

A total of 28 associations between IBD and different types of diseases were found (Table 1). Amongst these associations, the random meta-analytic model was used in 23 estimates (82.14\%), and the fixed meta-analytic model was used in five estimates (17.86\%). Ten (35.71\%) meta-analytic summary effect estimates were adjusted, while 18 (64.29\%) meta-analytic summary effect estimates were unadjusted. Overall, the summary effect estimates were significant in $92.86 \%$ estimates.

The result of evidence quality for each association is summarized in Table 2 and Supplemental Table 4. In total, the evidence quality was graded as high for $3.57 \%(n=1)$, moderate for $21.43 \%(n=6)$, low for $28.57 \%$ $(n=8)$, and very low for $46.43 \%(n=13)$. Large heterogeneity between studies is the main reason leading to a downgrade in the evidence quality. Fig. 3-5 and supplemental table 1-2 shows the subgroup results stratifying by the types of IBD, gender, ethnicity, age and other.

\section{The associations between IBD and cancers}


Moderate quality of evidence shows that there was positive associations between IBD and risk of thyroid cancer (OR=1.75; 95\% Cl, 1.48-2.07) (Table 2 and Supplemental Table 4) [29]. Low quality of evidence shows that IBD was associated with an increased risk of cervical cancer [27], intrahepatic cholangiocarcinoma [30], melanoma [31] and extrahepatic cholangiocarcinoma [30]. There was an association between IBD and increased risk of prostate cancer [26] and colorectal cancer [28], but the evidence quality was very low.

By stratifying based on the type of IBD, CD was significantly associated with an elevated risk of cervical cancer, while UC was not [27]. UC was increased the risk of thyroid cancer, while CD was not [29] (Fig. 3A-B). By stratifying based on ethnicity, IBD was associated with a higher risk of extrahepatic cholangiocarcinoma in Asians, but not in Non-Asians [30]; with an increased risk of melanoma in North Americans, but not in Europeans [31](Fig. 5). By stratifying based on age, IBD was associated with a higher risk of colorectal cancer in patients of age $\otimes 30$ years, but not in the patients age $\geq 30$ years (Supplemental Table 1) [28]. By stratifying based on study design, IBD was associated with an increased risk of thyroid cancer and melanoma in population-based studies, but not in hospital based studies [29, 31] (Supplemental Table 2). By stratifying based on the number of patients, IBD was associated with an increased risk of thyroid cancer in the studies with $\geq 10,000$ patients, but not in those with $\otimes 10,000$ patients[29]. Further, IBD increased risk of thyroid cancer in the patients who use immunosuppressants, but not in those who never use immunosuppressants [29].

\section{The associations between IBD and cardio-cerebro-vascular diseases}

Moderate quality of evidence shows that IBD was associated with an increased incidence of myocardial infarction ( $\mathrm{RR}=1.12 ; 95 \% \mathrm{Cl}, 1.05-1.21$ ) [34] (Table 2 and Supplemental Table 4). There are positive associations between IBD and stroke incidence [32], ischemic heart disease risk [33], cerebrovascular disease incidence [34], coronary heart disease incidence [34], venous thromboembolic risk [35], but the quality of evidence is low to very low. There are no clear associations between IBD and cardiovascular disease mortality and arterial thromboembolism [35], but the quality of evidence is low and very low.

By stratifying based on the type of IBD, UC was associated with and increased incidence of stroke, while CD did not [32] (Fig. 3A-B). By stratifying based on gender, IBD was associated with increased stroke incidence [32], ischemic heart disease risk [33], cerebrovascular disease incidence both in Male and Female [34] (Fig. 4). By stratifying based on ethnicity, IBD was associated with increased stroke incidence both in Asians and nonAsians [32] (Fig. 5). By stratifying based on the length of follow-up, IBD increased risk of ischemic heart disease in the patients who were follow-up for less than 5 years, but not in those who were follow-up for more than 5 years [33](Supplemental Table 2). By stratifying based on study design, IBD was associated with an increased risk of arterial thromboembolism in general patients, but not in hospitalized patients [35] (Supplemental Table 2). Further, IBD was associated with an increased risk mesenteric ischemia, but not associated with an increased risk peripheral artery disease [35].

\section{The associations between IBD and obstetrical diseases}

Moderate quality of evidence shows that IBD was associated with an increased incidence of preterm birth (OR=1.85; 95\% Cl, 1.67-2.05) and incidence of stillbirth (OR=1.57; 95\% Cl, 1.03-2.38) [36] (Table 2 and Supplemental Table 4). There are positive associations between IBD and incidence of small for gestational age birth weight and congenital anomalies, but the quality of evidence is low and very low. By stratifying 
based on the type of IBD, both UC and CD were associated with an increased incidence of preterm birth [36] (Fig. 3A-B).

\section{The associations between IBD and neuropsychiatric diseases}

There are positive associations between IBD and risk of Parkinson's disease, but the quality of evidence are very low [38] (Table 2 and Supplemental Table 4). By stratifying based on the type of IBD, both UC and CD were associated with an increased risk of Parkinson's disease [38] (Fig. 3A-B). By stratifying based on gender, IBD was increased risk of Parkinson's disease both in Male and Female (Fig. 4). By stratifying based on age, IBD was increased risk of Parkinson's disease in patients either younger than 65 years old or elder than 65 years old [38] (Supplemental Table 1).

\section{Association between IBD and otolaryngology and stomatology diseases}

High quality of evidence shows that IBD increased the risk of periodontitis (OR=4.55; 95\% $\mathrm{Cl}, 3.00-6.19)$ [41]. Low quality of evidence shows that IBD was associated with an increased risk of rosacea [43] (Table 2 and Supplemental Table 4). By stratifying based on ethnicity, IBD was associated with increased risk of rosacea both in Asians and Europeans [43] (Fig.5).

\section{Association between IBD and other diseases}

Moderate quality of evidence shows that IBD increased the prevalence of gallstone disease $(\mathrm{OR}=1.72 ; 95 \% \mathrm{Cl}$, 1.40-2.12) [40] and vitamin D deficiency (OR=1.64; 95\% Cl, 1.30-2.08)[42]. Very low quality of evidence indicates that IBD was associated with an increased risk of sexual dysfunction [37] and osteoporotic fracture [39] (Table 2 and Supplemental Table 4).

By stratifying based on the type of IBD, both CD and UC increased the risk of herpes zoster infection and the prevalence of vitamin D deficiency [44]; CD was associated with an increased prevalence of gallstone disease, but UC was not [40]. By stratifying based on gender, IBD was increased risk of sexual dysfunction both in male and ffemale [37] (Fig. 4). By stratifying based on ethnicity, IBD was increased the risk of herpes zoster infection both in Causations and Asians [44] (Fig. 5). By stratifying based on age, IBD was associated with an increased risk of sexual dysfunction only in male less than 50 years old and female less than 40 years old [37] ; with increased prevalence of vitamin D deficiency in adult, but not in pediatric [42]. IBD was only associated with an increased risk of vertebral fracture, but not associated with risk of hip, wrist and humeral fracture [39].

\section{Discussion}

\section{Principal findings}

Our umbrella review systematically summarized and evaluated existing evidence from meta-analyses on associations between IBD and diverse diseases. This umbrella review included 19 published meta-analyses that investigated on the association between IBD and 28 types of health outcomes. $64.29 \%$ of meta-analyses reported significant heterogeneity between studies. Only one meta-analysis indicated the existence of publication bias. The methodological qualities of the included meta-analyses were rated as moderate for $5.26 \%(n=1)$, low for $21.05 \%(n=4)$, and critically low for $73.68 \%(n=14)$. The evidence quality of the 
associations between IBD and various diseases was graded as high for $3.57 \%(n=1)$, moderate for $21.43 \%$ $(n=6)$, low for $28.57 \%(n=8)$, and very low for $46.43 \%(n=13)$.

\section{Possible explanations}

We found that IBD was associated with an increased risk of 26 types of different diseases. This result supports that the human body is an interconnected organic unit whose organs might be related to each other by their pathophysiology, such as the theory of the brain and intestine axis and the theory of the liver and intestine axis [45]. Identifying and removing risk factors can play an important role in the prevention and prediction of diseases. Therefore, comprehensively recognizing associations between IBD and diverse diseases may contribute to human health. However, $64.29 \%$ meta-analytic summary effect estimates were unadjusted for confounders (e.g., smoking and drinking). Nevertheless, the influence of confounding factors on the results cannot be ruled out.

This study shows that IBD, both UC and CD increased risk of periodontitis with high quality of evidence, demonstrating that IBD contributes to the prevalence of periodontitis. Both IBD and periodontitis are immunemediated inflammatory diseases influenced by genetic and environmental factors [46-48]. The immune responses of IBD are involved in the course of periodontitis [46-48]. The cytokines and mediators of inflammation might play an important role in linking association between IBD and periodontitis [49-51].

IBD was associated with an increased risk of thyroid cancer, incidence of myocardial infarction, incidence of preterm birth, incidence of stillbirth, prevalence of gallstone disease and prevalence of vitamin D deficiency with moderate quality of evidence. It indicates that IBD may play an important role in the pathogeny and development of these diseases. Chronic systemic inflammation may be a major mechanism explained the association between IBD and these diseases. Related research shows thyroid cancer and IBD may share a similar denominator in pathogenesis [52]. Reliable genetic data indicate that the extraintestinal manifestations and complications of IBD and the genetic risk loci of gallstones widely overlap, and the pathogenicity overlap between them has expanded from shared risk genes to unique shared biological pathways [53]. Inflammation triggers atherosclerosis-related processes, from plaque formation to thrombus rupture, leading to coronary heart disease [54].

The associations with low or very low quality of evidence between IBD and those diseases (e.g. prostate cancer, stroke, ischemic heart disease) indicate that these associations should be assessed with caution. Although quality of evidence for these associations were graded "low" or "very low," they might still provide ideas for clinicians. Most of the evidence quality was downgrade by inconsistency of meta-analyses. Therefore, these associations warrant further investigation.

Subgroup analyses shows that UC was increased the risk of thyroid cancer and the incidence of stroke, while CD was not; CD was associated with an increased prevalence of gallstone disease and risk of cervical cancer, but UC was not. These differences might be interpreted by not the same pathogeneses of UC and CD [46,55]. It also may be confused by confounders, which may exaggerate or minimize the effects. The risks of thyroid cancer, stroke, ischemic heart disease, sexual dysfunction and Parkinson's disease, and the incidence of coronary heart disease and cerebrovascular disease were increased in both male and female participants with $\mathrm{IBD}$, demonstrating that associations between IBD and these diseases might not be a gender-specific problem. 
Subgroup analyses shows that IBD was associated with an increased risk of extrahepatic cholangiocarcinoma in Asians, but not in non-Asians; IBD was related to an increased risk of melanoma in North Americans, but not Europeans. These findings indicate that ethnicity plays an important role in the association between IBD and these diseases. Different environmental exposures and genetic susceptibilities among various geographic areas may explain these differences $[3,47]$.

By stratifying based on age, IBD was associated with a higher risk of colorectal cancer in patients at the age of $₫ 30$ years old, but not in the patients at the age $\geq 30$ years old; with an increased risk of sexual dysfunction only in male less than 50 years old and female less than 40 years old; with increased prevalence of vitamin D deficiency in adult, but not in pediatric. These results demonstrate that age play an important role in the association between IBD and those diseases [56]. However, the included studies are affected by the sample size, and the conclusions drawn are not necessarily correct.

A previous study reported that disease behaviour remained stable in $91 \%$ of patients with IBD, after a median follow-up of six years [57]. This information might be able to explain why patients with IBD followed up with for a short duration were associated with an increased risk of ischemic heart disease, whereas patients followed up for a long period were not associated with such risk[33].

The methodological qualities of $94.74 \%$ of the included meta-analyses were low or critically low per AMSTAR2, suggesting that the results of these meta-analyses might be inconclusive. Twenty meta-analyses reported significant heterogeneity between studies. All of the included studies explored potential sources of heterogeneity by subgroup analyses. The sources of heterogeneity partly were type of $\operatorname{IBD}[27-29,31,34,42$, 43], disease activity and severity of IBD[33], the age of patient[33, 37, 42, 44], different ethnicity[30, 43, 44], different length of time of follow-up[33], study setting[35], and study design[30, 35]. However, some heterogeneity could not be readily explained in certain studies $[26,36]$, indicating that some associations between IBD and the risk of other diseases may be inflated or falsely positives.

A minority of meta-analyses reported notable publication bias. However, $60.71 \%$ of meta-analyses included less than 10 primary studies, which indicates that the results in this regard may not be reliable. Furthermore, associations between IBD and the risk of other diseases may be found among thousands of individuals, but only a small proportion of associations are recorded, and an even smaller fraction is finally published [58]. Moreover, in practice, positive results are probably easier to publish, while negative results may not be published [59]. These phenomena could lead to publication biases in the results.

\section{Comparison with other studies}

Our umbrella review supports some recommendations of existing guidelines, and adds evidence in several respects. We found that patients with IBD had a high risk of periodontitis with a high quality of evidence [41]. Considering the association between IBD and the risk of periodontitis may helpful for the diagnosis and treatment of periodontitis. However, a guideline recommending this association was not found. Thus, this evidence may be added to relevant guidelines in the future. A practical guideline stated increased disease activity of IBD has the greatest adverse effects upon a pregnancy [60], which was supported by our results that IBD increased the risks of preterm birth and stillbirth with a moderate level of evidence quality [36]. The guideline of Crohn's disease by the American College of Gastroenterology (ACG) stated that gallstone disease 
and metabolic bone diseases (associated with vitamin D deficiency) are complications of Crohn's disease [61], which was also supported by our results. However, the moderate quality of evidence for associations between IBD and an increased risk of thyroid cancer and incidence of myocardial infarction are not stated in the guideline yet [61]. This evidence might be helpful in future disease prevention and treatment efforts and could be added to the guidelines in the future.

Prevention again venous thromboembolism (strong recommendation, low quality of evidence) in patients with IBD are included in some guidelines [60,62]. The Canadian Association of Gastroenterology has also reached a consensus on the risk, prevention, and treatment of venous thromboembolism in patients with IBD [63]. Both venous and arterial thromboembolisms are the complications of Crohn's disease [61]. However, we found that IBD was associated with an increased risk of venous thromboembolism with a very low evidence quality [35], while IBD was not associated with an increased risk of arterial thromboembolism also per a very low quality of evidence [35]. The type of IBD may be one of the causes leading to this difference. Further research should be conducted to confirm whether IBD is associated with an arterial thromboembolic risk.

Additionally, guidelines recommended that patients with IBD should undergo cancer (cervical cancer, melanoma, colorectal cancer, and prostate cancer) screening, herpes zoster infection prevention, osteopenia monitoring, and fracture risk assessment $[61,62,64-66]$. These recommendations were confirmed by our results with low or very low qualities evidence. Although the quality of evidence of these associations was low, they still may provide guidance for clinicians.

So far, we have not found a review of the relationship between IBD and other diseases after searching. However, through our efforts, we have found studies on other diseases related to IBD, and the results show that the quality of the evidence is relatively low.

\section{Strengths, weaknesses, and future studies}

There are several strengths in our umbrella review. At first, this umbrella review firstly summarized and reevaluated the evidence of associations between IBD and diverse diseases from published meta-analyses of observational studies. Previous studies have demonstrated the strengths of umbrella reviews [67-69]. Second, we identified the methodological quality of SRs/Mets by AMSTAR2, and evaluated the evidence quality of each outcome by GRADE. These two appraisal tools are critical and valid, being used worldwide [20-22]. Confirming the evidence is important for the recommendation of guidelines [71,72]. Using GRADE approach to re-evaluate the quality of evidence, this umbrella review adds evidence about associations between IBD and diverse diseases for clinical decision-makers and developers of guideline. Moreover, this umbrella review used systematic methods, including a comprehensive search of seven literature databases, an independent study selection, extraction and assessment by two reviewers. Although the selection and evaluation of the included studies may be subjective, a third investigator checked the results and a fourth investigator arbitrated all disagreement, which may have reduced the reduce subjectivity. Lastly, we found some deficiencies in existing published meta-analyses through this umbrella review, which may contribute to future research improvements. We also found some evidence of an association between IBD and other diseases (diseases for which there were original studies but which have not yet been meta-analyzed, such as diabetes [72]) were absent, which should be considered in future studies. 
However, there were several weaknesses in our umbrella review. First, we only included meta-analyses and systematic reviews with meta-analyses. Some primary studies which did not develop to meta-analyses were not been completely included in this umbrella review [72-74], which might induce conclusion bias of this study. Second, we assessed heterogeneity by $\mathrm{I}^{2}$ which was influenced by sample size and the accuracy of the GRADE assessment might be affected. Moreover, although AMSTAR 2 and GRADE are both validated tools, the use of other tools (e.g., Risk of Bias in Systematic Reviews) could have led to different conclusions regarding the quality of the methodology and the evidence [75]. Finally, the included primary studies were observational prospective or retrospective investigations, which are prone to confounding bias and retrospective bias.

Therefore, a large body of well-designed prospective studies should be carried out to better evaluate associations between IBD and the risk of multisystem diseases, especially those associations showing low or very low qualities of evidence. Future prospective studies should focus confounder information (e.g., family history) to better map the association between IBD and other diseases. In this umbrella review, the methodological qualities of $90 \%$ of the included meta-analyses were low or critically low. Meta-analyses should be conducted using a standard method in future studies, providing reliable evidence.

\section{Conclusions}

In conclusion, associations between IBD and diverse diseases have been widely studied by published metaanalyses, and most summary meta-analytic estimates yielded nominally significant results. However, only the association between IBD and the risk of periodontitis experienced robust support without hints of bias. Therefore, associations with low or very low quality need to be interpreted with caution. Well-designed prospective studies and meta-analyses are required to confirm these associations. In addition, careful planning and close monitoring should be adopted to discover and minimize the risk of diverse diseases in patients with IBD.

\section{Declarations}

\section{Funding}

This work was funded by National Natural Science Foundation of China (no. 81573914, no.81460723 and no.82004299); the special foundation for science and technology of guangxi administration of traditional Chinese medicine (GZZX15-02); the project of improving the evidence-based ability of specialized diseases (gastroesophageal reflux disease) in the field of TCM digestion (2019XZZX-XH003).

\section{Acknowledgments}

We thank LetPub (www.letpub.com) for its linguistic assistance during the preparation of this manuscript.

\section{Ethical approval}


Not applicable.

\section{Declaration of interests}

None.

\section{Author Contributions}

Liqun Li, Qianli Cen and Lijian Liu contributed equally to this work. Qianli Cen wrote the protocol. Lijian Liu and Jinxiu Wei independently searched the databases and conducted the AMSTAR2 classification. Liqun Li and Qianli Cen screened the articles according to the eligibility and exclusion criteria, and extracted the data. Jinjing Tan and Yalu Chen conducted GRADE classifications. Jianfeng Li checked the result of AMSTAR2 classification, and Yuanyuan Liu checked the data and results. Liqun Li and Guangwen Chen conducted statistical analyses. Li Liqun, Cen Qianli and Lijian Liu wrote the draft of the paper. Jinxiu Wei, Tan Jinjing and Yuanyuan Liu revised the paper. Xie Sheng was contributed in concept design, guidance and arbitrating all discrepancies, and was also responsible for the final content. All authors approved the final manuscript and attested that it has not been previously published.

\section{References}

1. de Lange KM, Moutsianas L, Lee JC, Lamb CA, Luo Y, Kennedy NA, et al. Genome-wide association study implicates immune activation of multiple integrin genes in inflammatory bowel disease. Nat Genet. 2017;49(2):256-61.

2. Piovani D, Danese S, Peyrin-Biroulet L, Nikolopoulos GK, Lytras T, Bonovas S. Environmental Risk Factors for Inflammatory Bowel Diseases: An Umbrella Review of Meta-analyses. Gastroenterology. 2019;157(03):647-59. e4.

3. Friedman S, Norgard BM. Confirming Complexity: Assessing Environmental and Genetic Risk Factors for Inflammatory Bowel Disease. Gastroenterology. 2019;156(8):2124-5.

4. Ng SC, Shi HY, Hamidi N, Underwood FE, Tang W, Benchimol El, et al. Worldwide incidence and prevalence of inflammatory bowel disease in the 21 st century: a systematic review of population-based studies. Lancet. 2017;390(10114):2769-78.

5. Ye Y, Manne S, Treem WR, Bennett D. Prevalence of Inflammatory Bowel Disease in Pediatric and Adult Populations: Recent Estimates From Large National Databases in the United States, 2007-2016. Inflamm Bowel Dis. 2020;26(4):619-25.

6. Ng SC, Kaplan GG, Tang W, Banerjee R, Adigopula B, Underwood FE, et al. Population Density and Risk of Inflammatory Bowel Disease: A Prospective Population-Based Study in 13 Countries or Regions in AsiaPacific. Am J Gastroenterol. 2019;114(1):107-15.

7. Jairath V, Feagan BG. Global burden of inflammatory bowel disease. Lancet Gastroenterol Hepatol. 2020;5(1):2-3. 
8. Pedersen N, Duricova D, Elkjaer M, Gamborg M, Munkholm P, Jess T. Risk of extra-intestinal cancer in inflammatory bowel disease: meta-analysis of population-based cohort studies. Am J Gastroenterol. 2010;105(7):1480-7.

9. Zou ZY, Shen B, Fan JG. Systematic Review With Meta-analysis: Epidemiology of Nonalcoholic Fatty Liver Disease in Patients With Inflammatory Bowel Disease. Inflamm Bowel Dis. 2019;25(11):1764-72.

10. Singh S, Singh H, Loftus EV, Pardi DS. Risk of cerebrovascular accidents and ischemic heart disease in patients with inflammatory bowel disease: a systematic review and meta-analysis. Clin Gastroenterol Hepatol. 2014;12(03):382-93. :.e1: quiz e22..

11. Zhang S, Gong TT, Liu FH, Jiang YT, Sun H, Ma XX, et al. Global, Regional, and National Burden of Endometrial Cancer, 1990-2017: Results From the Global Burden of Disease Study. 2017Front Oncol. 2019;9:1440.

12. Paik JM, Golabi P, Younossi Y, Mishra A, Younossi ZM. Changes in the Global Burden of Chronic Liver Diseases From 2012 to 2017: The Growing Impact of Nonalcoholic Fatty Liver Disease. Hepatology. 2020;72(5):1605-16.

13. India State-Level Disease Burden Initiative CVD Collaborators. The changing patterns of cardiovascular diseases and their risk factors in the states of India: the Global Burden of Disease Study 1990-2016. Lancet Glob Health. 2018;6(12):e1339-51.

14. Hidalgo DF, Boonpheng B, Phemister J, Hidalgo J, Young M. Inflammatory Bowel Disease and Risk of Osteoporotic Fractures: A Meta-Analysis. Cureus.2019;11(9):e5810.

15. Komaki Y, Komaki F, Micic D, Ido A, Sakuraba A. Risk of Fractures in Inflammatory Bowel Diseases: A Systematic Review and Meta-Analysis. J Clin Gastroenterol. 2019;53(6):441-8.

16. Aromataris E, Fernandez R, Godfrey CM, Khalil H, Tungpunkom P. Summarizing systematic reviews: methodological development, conduct and reporting of an umbrella review approach. Int J Evid Based Healthc. 2015;13(3):132-40.

17. Booth A, Clarke M, Dooley G, Ghersi D, Moher D, Petticrew M, et al. The nuts and bolts of PROSPERO: an international prospective register of systematic reviews. Syst Rev. 2012;1:2.

18. Stroup DF, Berlin JA, Morton SC, Olkin I, Williamson GD, Rennie D, et al. Meta-analysis of observational studies in epidemiology: a proposal for reporting. Meta-analysis Of Observational Studies in Epidemiology (MOOSE) group. Jama. 2000;283(15):2008-12.

19. Shea BJ, Reeves BC, Wells G, Wells G, Thuku M, Hamel C, et al. AMSTAR 2: a critical appraisal tool for systematic reviews that include randomised or non-randomised studies of healthcare interventions, or both. Bmj. 2017;358:j4008.

20. Lorenz RC, Matthias K, Pieper D, Wegewitz U, Morche J, Nocon M, et al. A psychometric study found AMSTAR 2 to be a valid and moderately reliable appraisal tool. Syst Rev. 2019;114:133-40.

21. Guyatt G, Oxman AD, AkI EA, Kunz R, Vist G, Brozek J, et al. GRADE guidelines: 1. Introduction-GRADE evidence profiles and summary of findings tables. J Clin Epidemiol. 2011;64(4):383-94.

22. Balshem H, Helfand M, Schunemann HJ, Oxman AD, Kunz R, Brozek J, et al. GRADE guidelines: 3. Rating the quality of evidence. J Clin Epidemiol. 2011;64(4):401-6. 
23. Sterne JA, Gavaghan D, Egger M. Publication and related bias in meta-analysis: power of statistical tests and prevalence in the literature. J Clin Epidemiol. 2000;53(11):1119-29.

24. Melsen WG, Bootsma MC, Rovers MM, Bonten MJ. The effects of clinical and statistical heterogeneity on the predictive values of results from meta-analyses. Clin Microbiol Infect. 2014;20(2):123-9.

25. DerSimonian R, Laird N. Meta-analysis in clinical trials revisited. Contemp Clin Trials. 2015;45(PtA):13945.

26. Chen M, Yuan C, Xu T. An increase in prostate cancer diagnosis during inflammatory bowel disease: A systematic review and meta-analysis. Clin Res Hepatol Gastroenterol. 2020;44(3):302-9.

27. Wang P, Yan H, Wang Z, Dai L, Xu S, Wang B. Inflammatory bowel disease and risk of cervical cancer: a meta-analysis. Int J Colorectal Dis. 2014;29(8):1023-4.

28. Lutgens MW, van Oijen MG, van der Heijden GJ, Vleggaar FP, Siersema PD, Oldenburg B. Declining risk of colorectal cancer in inflammatory bowel disease: an updated meta-analysis of population-based cohort studies. Inflamm Bowel Dis. 2013;19(4):789-99.

29. Cao L. Assessment of thyroid cancer risk in more than 334,000 patients with inflammatory bowel disease: a case-control study and a meta-analysis. World J Surg Oncol. 2018;16(1):182.

30. Huai JP, Ding J, Ye XH, Chen YP. Inflammatory bowel disease and risk of cholangiocarcinoma: evidence from a meta-analysis of population-based studies. A Asian Pac J Cancer Prev. 2014;15(8):3477-82.

31. Singh S, Nagpal SJ, Murad MH, Yadav S, Kane SV, Pardi DS, et al. Inflammatory bowel disease is associated with an increased risk of melanoma: a systematic review and meta-analysis. Clin Gastroenterol Hepatol. 2014;12(2):210-8.

32. Yuan M, Zhou HY, Xiao XL, Wang ZQ, Yin XP. Inflammatory bowel disease and risk of stroke: A metaanalysis of cohort studies. Int J Cardiol. 2016;202:106-9.

33. Feng W, Chen G, Cai D, Zhao S, Cheng J, Shen H. Inflammatory Bowel Disease and Risk of Ischemic Heart Disease: An Updated Meta-Analysis of Cohort Studies. J Am Heart Assoc. 2017 Aug;6(8):e005892.

34. Sun HH, Tian F. Inflammatory bowel disease and cardiovascular disease incidence and mortality: A metaanalysis. Eur J Prev Cardiol. 2018;25(15):1623-31.

35. Fumery M, Xiaocang C, Dauchet L, Gower-Rousseau C, Peyrin-Biroulet L, Colombel JF. Thromboembolic events and cardiovascular mortality in inflammatory bowel diseases: a meta-analysis of observational studies. J Crohns Colitis. 2014;8(6):469-79.

36. O'Toole A, Nwanne O, Tomlinson T. Inflammatory Bowel Disease Increases Risk of Adverse Pregnancy Outcomes: A Meta-Analysis. Dig Dis Sci. 2015;60(9):2750-61.

37. Zhao S, Wang J, Liu Y, Luo L, Zhu Z, Li E, et al. Inflammatory Bowel Diseases Were Associated With Risk of Sexual Dysfunction in Both Sexes: A Meta-analysis. Inflamm Bowel Dis. 2019;25(4):699-707.

38. Zhu F, Li C, Gong J, Zhu W, Gu L, Li N. The risk of Parkinson's disease in inflammatory bowel disease: A systematic review and meta-analysis. Dig Liver Dis. 2019;51(1):38-42.

39. Szafors P, Che H, Barnetche T, Morel J, Gaujoux-Viala C, Combe B, et al. Risk of fracture and low bone mineral density in adults with inflammatory bowel diseases. A systematic literature review with metaanalysis. Osteoporos Int. 2018;29(11):2389-97. 
40. Zhang FM, Xu CF, Shan GD, Chen HT, Xu GQ. Is gallstone disease associated with inflammatory bowel diseases? A meta-analysis. J Dig Dis. 2015;16(11):634-41.

41. Papageorgiou SN, Hagner M, Nogueira AV, Franke A, Jäger A, Deschner J. Inflammatory bowel disease and oral health: systematic review and a meta-analysis. J Clin Periodontol. 2017;44(4):382-93.

42. Del Pinto R, Pietropaoli D, Chandar AK, Ferri C, Cominelli F. Association Between Inflammatory Bowel Disease and Vitamin D Deficiency: A Systematic Review and Meta-analysis. Inflamm Bowel Dis. 2015;21(11):2708-17.

43. Han J, Liu T, Zhang M, Wang A. The relationship between inflammatory bowel disease and rosacea over the lifespan: A meta-analysis.Clin Res Hepatol Gastroenterol.2019 08;43(4) :497-502.

44. Ning L, Liu R, Li S, Shan G, Du H, Zhang J, et al. Increased risk of herpes zoster infection in patients with inflammatory bowel disease: a meta-analysis of cohort studies. Eur J Clin Microbiol Infect Dis. 2020;39(2):219-27.

45. Gracie DJ, Guthrie EA, Hamlin PJ, Ford AC, et al. TBi-directionality of Brain-Gut Interactions in Patients With Inflammatory Bowel Disease. Gastroenterology. 2018;154(6):1635-46.e3.

46. Liu TC, Stappenbeck TS. Genetics and Pathogenesis of Inflammatory Bowel Disease. Annu Rev Pathol. 2016;11:127-48.

47. Ng SC, Bernstein CN, Vatn MH, Lakatos PL, Loftus EV, Tysk C, et al. Geographical variability environmental risk factors in inflammatory bowel diseaseGut. 2013;62(4):630-49.

48. Meyle J, Chapple I, Fumery M, Merle V, Laberenne JE. Molecular aspects of the pathogenesis of periodontitis. Periodontol 2000. 2015;69(1):7-17.

49. Neurath MF. Cytokines in inflammatory bowel disease. Nature reviews Immunology. 2014;14:329-42.

50. Bunte K, Beikler T. Th17 Cells and the IL-23/IL-17 Axis in the Pathogenesis of Periodontitis and ImmuneMediated Inflammatory Diseases. Int J Mol Sci. 2019;20(14):3394.

51. Yucel-Lindberg T, Bage T. Inflammatory mediators in the pathogenesis of periodontitis. Expert Rev Mol Med. 2013;15:e7.

52. Wadhwa V, Lopez R, Shen B. Crohn's Disease Is Associated with the Risk for Thyroid Cancer. Inflamm Bowel Dis Inflamm Bowel Dis. 2016;22(12):2902-6.

53. van Sommeren S, Janse M, Karjalainen J, Fehrmann R, Franke L, Fu J, et al. Extraintestinal manifestations and complications in inflammatory bowel disease: from shared genetics to shared biological pathways. Inflamm Bowel Dis. 2014;20(6):987-94.

54. Hatoum OA, Binion DG. The vasculature and inflammatory bowel disease: contribution to pathogenesis and clinical pathology. Inflamm Bowel Dis. 2005;11(3):304-13.

55. Chapuy L, Bsat M, Rubio M, Harvey F, Motta V, Schwenter F, et al. Transcriptomic analysis and High dimensional phenotypic mapping of mononuclear phagocytes in mesenteric lymph nodes reveal differences between ulcerative colitis and Crohn's disease. J Crohns Colitis. 2020;14(3):393-405.

56. Charpentier C, Salleron J, Savoye G, et al. Natural history of elderly-onset inflammatory bowel disease: a population-based cohort study. Gut. 2014;63(3):423-32.

57. Duricova D, Burisch J, Jess T, Gower-Rousseau C, Lakatos PL. Age-related differences in presentation and course of inflammatory bowel disease: an update on the population-based literature. J Crohns Colitis. 
2014;8(11):1351-61.

58. Ioannidis JP. The importance of potential studies that have not existed and registration of observational data sets. JAMA. 2012;308(6):575-6.

59. Sridharan L, Greenland P. Editorial policies and publication bias: the importance of negative studies. Arch Intern Med. 2009;169(11):1022-3.

60. Friedman S, McElrath TF, Wolf JL. Management of fertility and pregnancy in women with inflammatory bowel disease: a practical guide. Inflamm Bowel Dis. 2013;19(13):2937-48.

61. Lichtenstein GR, Loftus EV, Isaacs KL, Regueiro MD, Gerson LB, Sands BE. ACG Clinical Guideline: Management of Crohn's Disease in Adults. Am J Gastroenterol. 2018;113(4):481-517.

62. Rubin DT, Ananthakrishnan AN, Siegel CA. ACG Clinical Guideline: Ulcerative Colitis in Adults. Am J Gastroenterol. 2019;114(3):384-413.

63. Nguyen GC, Bernstein CN, Bitton A, Chan AK, Griffiths AM, Leontiadis GI, et al. Consensus statements on the risk, prevention, and treatment of venous thromboembolism in inflammatory bowel disease: Canadian Association of Gastroenterology. Gastroenterology 2014; 146(3): 835 - 48.e6.

64. Farraye FA, Melmed GY, Lichtenstein GR, Kane SV. ACG Clinical Guideline: Preventive Care in Inflammatory Bowel Disease. Am J Gastroenterol. 2017;112(2):241-58.

65. Moscandrew M, Mahadevan U, Kane S. General health maintenance in IBD. Inflamm Bowel Dis.2009 Sep;15(9):1399-409.

66. Cairns SR, Scholefield JH, Steele RJ, Dunlop MG, Thomas HJ, Evans GD, et al. Guidelines for colorectal cancer screening and surveillance in moderate and high risk groups (update from 2002). Gut. 2010;59(5):666-89.

67. Bracken MB. SSRIs and autism: interpreting an umbrella review. Lancet Psychiatry. 2019;6(11):893.

68. Dragioti E, Solmi M, Favaro A, et al. Association of Antidepressant Use With Adverse Health Outcomes: A Systematic Umbrella Review. JAMA psychiatry 2019.

69. Barbui C, Purgato M, Abdulmalik J, Fusar-Poli P, Dazzan P, Thompson T, et al. Efficacy of psychosocial interventions for mental health outcomes in low-income and middle-income countries: an umbrella review. JAMA Psychiatry. 2019;76(12):1241-55.

70. Guyatt GH, Oxman AD, Vist GE, Kunz R, Falck-Ytter Y, Alonso-Coello P, et al. GRADE: an emerging consensus on rating quality of evidence and strength of recommendations. Bmj. 2008;336(7650):924-6.

71. Maymone MBC, Gan SD, Bigby M. Evaluating the strength of clinical recommendations in the medical literature: GRADE, SORT, and AGREE. J Invest Dermatol. 2014;134(10):1-5.

72. Jess T, Jensen BW, Andersson M, Villumsen M, Allin KH. Inflammatory Bowel Disease Increases Risk of Type 2 Diabetes in a Nationwide Cohort Study. Clin Gastroenterol Hepatol. 2020;18(4):881-8.e1.

73. Wang LH, Yang YJ, Cheng WC, Wang WM, Lin SH, Shieh CC. Higher Risk for Hematological Malignancies in Inflammatory Bowel Disease: A Nationwide Population-based Study in Taiwan. Am J Gastroenterol. 2016;111(9):1313-9.

74. Kantso B, Simonsen J, Hoffmann S, Valentiner-Branth P, Petersen AM, Jess T. Inflammatory Bowel Disease Patients Are at Increased Risk of Invasive Pneumococcal Disease: A Nationwide Danish Cohort Study 1977-2013. Am J Gastroenterol. 2015;110(11):1582-7. 
75. Gates A, Gates M, Duarte G, Cary M, Becker M, Prediger B, et al. Evaluation of the reliability, usability, and applicability of AMSTAR, AMSTAR 2, and ROBIS: protocol for a descriptive analytic study. Syst Rev. 2018;7(1):85.

\section{Tables}

Table 1 Description of the 19 included meta-analyses 


\begin{tabular}{|c|c|c|c|c|c|c|c|c|c|c|}
\hline Studies & Outcomes & $\begin{array}{l}\text { No of } \\
\text { studies }\end{array}$ & $\begin{array}{l}\text { No of } \\
\text { participants } \\
\text { / cases }\end{array}$ & $\begin{array}{l}\text { Meta- } \\
\text { analytic } \\
\text { model } \\
\text { used }\end{array}$ & $\begin{array}{l}\text { Type } \\
\text { of } \\
\text { metric }\end{array}$ & $\begin{array}{l}\text { Effect } \\
\text { size } \\
(95 \% \mathrm{CI})\end{array}$ & $\begin{array}{l}P \\
\text { value } \\
\text { of } Q \\
\text { test }\end{array}$ & $\mathrm{I}^{2}$ & $\begin{array}{l}\text { P value of } \\
\text { Egger's } \\
\text { Test / } \\
\text { funnel } \\
\text { plots }\end{array}$ & $\begin{array}{l}\text { Whether } \\
\text { publication } \\
\text { bias } \\
\text { exists? }\end{array}$ \\
\hline \multicolumn{11}{|c|}{ Associations between IBD and cancers } \\
\hline Chen,2019[26] & $\begin{array}{l}\text { Prostate cancer } \\
\text { risk }\end{array}$ & $\begin{array}{l}1 \mathrm{CCS}, 9 \\
\mathrm{CS}\end{array}$ & $\begin{array}{l}282935 / \\
\mathrm{NR}\end{array}$ & Random & OR & $\begin{array}{l}1.78 \\
(1.32, \\
2.41)\end{array}$ & 0.000 & $88 \%$ & 0.10 & No \\
\hline Wang, 2014[27] & $\begin{array}{l}\text { Cervical cancer } \\
\text { risk }\end{array}$ & $7 \mathrm{CS}$ & 83,866 / 253 & Fixed & SIR & $\begin{array}{l}1.20 \\
(1.00 \\
1.45)\end{array}$ & 0.049 & $24 \%$ & 0.55 & No \\
\hline Lutgens, 2013[28] & $\begin{array}{l}\text { Colorectal cancer } \\
\text { risk }\end{array}$ & $11 \mathrm{CS}$ & $\begin{array}{l}544,552 / \\
334\end{array}$ & Random & SIR & $\begin{array}{l}1.70 \\
(1.20 \\
2.20)\end{array}$ & NR & $64 \%$ & Symmetry & No \\
\hline Cao,2018[29] & Thyroid cancer risk & $8 \mathrm{CCS}$ & $\begin{array}{l}4,652,390 / \\
4,984\end{array}$ & Fixed & OR & $\begin{array}{l}1.75 \\
(1.48 \\
2.07)\end{array}$ & 0.31 & $15 \%$ & Symmetry & No \\
\hline \multirow[t]{2}{*}{ Huai, 2014[30] } & $\begin{array}{l}\text { Intrahepatic } \\
\text { cholangiocarcinoma } \\
\text { risk }\end{array}$ & $\begin{array}{l}4 \\
\mathrm{CCS}, 1 \mathrm{CS}\end{array}$ & $\begin{array}{l}222,248 / \\
4,939\end{array}$ & Random & $\mathrm{OR}^{\mathrm{a}}$ & $\begin{array}{l}2.61 \\
(1.72, \\
3.95)\end{array}$ & 0.01 & $73 \%$ & 0.12 & No \\
\hline & $\begin{array}{l}\text { Extrahepatic } \\
\text { cholangiocarcinoma } \\
\text { risk }\end{array}$ & $\begin{array}{l}2 \mathrm{CCS}, 1 \\
\mathrm{CS}\end{array}$ & $\begin{array}{l}126,413 / \\
2,803\end{array}$ & Random & $\mathrm{OR}^{\mathrm{a}}$ & $\begin{array}{l}1.47 \\
(1.10, \\
1.97)\end{array}$ & 0.28 & $22 \%$ & 0.12 & No \\
\hline Singh,2014[31] & Melanoma risk & $12 \mathrm{CS}$ & $\begin{array}{l}172,837 / \\
179\end{array}$ & Random & $\mathrm{OR}^{\mathrm{a}}$ & $\begin{array}{l}1.37 \\
(1.10 \\
1.70)\end{array}$ & 0.18 & $26 \%$ & 0.43 & No \\
\hline \multicolumn{11}{|c|}{ Associations between IBD and cardio-cerebro-vascular diseases } \\
\hline Yuan,2016[32] & Stroke incidence & $8 \mathrm{CS}$ & $\begin{array}{l}1,162,318 \\
/ 18,762\end{array}$ & Random & $\mathrm{RR}^{\mathrm{a}}$ & $\begin{array}{l}1.32 \\
(1.20 \\
1.44)\end{array}$ & 0.00 & $85 \%$ & NR & No \\
\hline Feng,2017[33] & $\begin{array}{l}\text { Ischemic heart } \\
\text { disease risk }\end{array}$ & $12 \mathrm{CS}$ & $\begin{array}{l}5,645,367 / \\
\text { NR }\end{array}$ & Random & $\mathrm{RR}^{\mathrm{a}}$ & $\begin{array}{l}1.24 \\
(1.14 \\
1.35)\end{array}$ & $<0.01$ & $87 \%$ & 0.29 & No \\
\hline \multirow[t]{3}{*}{ Sun,2018[34] } & $\begin{array}{l}\text { Cerebrovascular } \\
\text { disease incidence }\end{array}$ & $6 \mathrm{CS}$ & $\mathrm{NR} / \mathrm{NR}$ & Random & $\mathrm{RR}$ & $\begin{array}{l}1.25 \\
(1.08, \\
1.44)\end{array}$ & $\begin{array}{l}< \\
0.01\end{array}$ & $91 \%$ & $\square 0.1$ & No \\
\hline & $\begin{array}{l}\text { Coronary heart } \\
\text { disease incidence }\end{array}$ & $6 \mathrm{CS}$ & NR / NR & Random & $\mathrm{RR}$ & $\begin{array}{l}1.17 \\
(1.07 \\
1.27)\end{array}$ & $\begin{array}{l}< \\
0.01\end{array}$ & $83 \%$ & $\square 0.1$ & No \\
\hline & $\begin{array}{l}\text { Myocardial } \\
\text { infarction } \\
\text { incidence }\end{array}$ & $4 \mathrm{CS}$ & NR / NR & Fixed & $\mathrm{RR}$ & $\begin{array}{l}1.12 \\
(1.05 \\
1.21)\end{array}$ & 0.75 & $0 \%$ & $\square 0.1$ & No \\
\hline \multirow[t]{3}{*}{ Fumery,2014[35] } & $\begin{array}{l}\text { Venous } \\
\text { thromboembolic } \\
\text { risk }\end{array}$ & $\begin{array}{l}9 \mathrm{CS}, 1 \\
\mathrm{CCS}\end{array}$ & $\begin{array}{l}940,572,339 \\
/ \mathrm{NR}\end{array}$ & Random & $\mathrm{RR}$ & $\begin{array}{l}1.96 \\
(1.67, \\
2.30)\end{array}$ & $<0.01$ & $99 \%$ & 0.93 & No \\
\hline & $\begin{array}{l}\text { Arterial } \\
\text { thromboembolism } \\
\text { risk }\end{array}$ & $\begin{array}{l}8 \quad \mathrm{CS}, 1 \\
\mathrm{CCS}\end{array}$ & $\begin{array}{l}22,472,601 / \\
\text { NR }\end{array}$ & Random & $\mathrm{RR}$ & $\begin{array}{l}1.15 \\
(0.91 \\
1.45)\end{array}$ & $<0.01$ & $97 \%$ & 0.93 & No \\
\hline & $\begin{array}{l}\text { Cardiovascular } \\
\text { disease mortality }\end{array}$ & $15 \mathrm{CS}$ & 69,383 / NR & Random & SMR & $\begin{array}{l}1.03 \\
(0.93 \\
1.14)\end{array}$ & $<0.01$ & $70 \%$ & 0.47 & No \\
\hline \multicolumn{11}{|c|}{ Associations between IBD and obstetrical diseases } \\
\hline \multirow[t]{4}{*}{ O'Toole,2015[36] } & $\begin{array}{l}\text { Preterm birth } \\
\text { incidence }\end{array}$ & $23 \mathrm{CS}$ & $13,033 / \mathrm{NR}$ & Random & OR & $\begin{array}{l}1.85 \\
(1.67 \\
2.05)\end{array}$ & 0.05 & $31 \%$ & 0.93 & No \\
\hline & $\begin{array}{l}\text { Small for } \\
\text { gestational age } \\
\text { birth weight } \\
\text { incidence }\end{array}$ & $13 \mathrm{CS}$ & $\begin{array}{l}4,144,549 / \\
118,523\end{array}$ & Random & OR & $\begin{array}{l}1.36 \\
(1.16 \\
1.60)\end{array}$ & 0.01 & $56 \%$ & Symmetry & No \\
\hline & $\begin{array}{l}\text { Congenital } \\
\text { anomalies } \\
\text { incidence }\end{array}$ & $11 \mathrm{CS}$ & $\begin{array}{l}3,336,345 / \\
120,312\end{array}$ & Random & OR & $\begin{array}{l}1.29 \\
(1.05 \\
1.58)\end{array}$ & 0.05 & $46 \%$ & Asymmetry & Yes \\
\hline & Stillbirth incidence & $10 \mathrm{CS}$ & $\begin{array}{l}2,973,200 / \\
12,326\end{array}$ & Random & OR & $\begin{array}{l}1.57 \\
(1.03 \\
2.38)\end{array}$ & 0.17 & $30 \%$ & Symmetry & No \\
\hline \multicolumn{11}{|c|}{ Associations between IBD and neuropsychiatric diseases } \\
\hline Zhu,2019[38] & $\begin{array}{l}\text { Parkinson's disease } \\
\text { risk }\end{array}$ & $\begin{array}{l}3 \quad \mathrm{CS}, 1 \\
\mathrm{CCS}\end{array}$ & $\begin{array}{l}187,791,256 \\
/ 43,244\end{array}$ & Random & $\mathrm{RR}^{\mathrm{a}}$ & $\begin{array}{l}1.41 \\
(1.19 \\
1.66)\end{array}$ & 0.003 & $83 \%$ & 0.62 & No \\
\hline
\end{tabular}




\begin{tabular}{|c|c|c|c|c|c|c|c|c|c|c|}
\hline Studies & Outcomes & $\begin{array}{l}\text { No of } \\
\text { studies }\end{array}$ & $\begin{array}{l}\text { No of } \\
\text { participants } \\
\text { / cases }\end{array}$ & $\begin{array}{l}\text { Meta- } \\
\text { analytic } \\
\text { model } \\
\text { used }\end{array}$ & $\begin{array}{l}\text { Type } \\
\text { of } \\
\text { metric }\end{array}$ & $\begin{array}{l}\text { Effect } \\
\text { size } \\
(95 \% \mathrm{CI})\end{array}$ & $\begin{array}{l}P \\
\text { value } \\
\text { of } Q \\
\text { test }\end{array}$ & $\mathrm{I}^{2}$ & $\begin{array}{l}\text { P value of } \\
\text { Egger's } \\
\text { Test / } \\
\text { funnel } \\
\text { plots }\end{array}$ & $\begin{array}{l}\text { Whether } \\
\text { publication } \\
\text { bias } \\
\text { exists? }\end{array}$ \\
\hline \multicolumn{11}{|c|}{ Associations between IBD and otolaryngology and stomatology diseases } \\
\hline Han,2019[43] & Rosacea risk & $\begin{array}{l}2 \mathrm{CCS}, 4 \\
\mathrm{CSS}\end{array}$ & $\begin{array}{l}4,726,070 / \\
\mathrm{NR}\end{array}$ & Fixed & $\mathrm{RR}^{\mathrm{a}}$ & $\begin{array}{l}1.66 \\
(1.50, \\
1.84)\end{array}$ & 0.09 & $48 \%$ & $>0.05$ & No \\
\hline Papageorgiou, 2017[41] & $\begin{array}{l}\text { Periodontitis } \\
\text { prevalence }\end{array}$ & $4 \mathrm{CS}$ & $811 / N R$ & Random & OR & $\begin{array}{l}4.55 \\
(3.00, \\
6.19)\end{array}$ & NR & $0 \%$ & NR & No \\
\hline \multicolumn{11}{|c|}{ Associations between IBD and other diseases } \\
\hline Zhao,2019[37] & $\begin{array}{l}\text { Sexual dysfunction } \\
\text { risk }\end{array}$ & $\begin{array}{l}5 \text { CCS,2 } \\
\text { CS,1 } \\
\text { CSS }\end{array}$ & $\begin{array}{l}352,977 / \\
35,885\end{array}$ & Random & $\mathrm{RR}$ & $\begin{array}{l}1.56 \\
(1.28 \\
1.89)\end{array}$ & 0.00 & $80 \%$ & 0.24 & No \\
\hline Szafors, 2018[39] & $\begin{array}{l}\text { Osteoporotic } \\
\text { fractures risk }\end{array}$ & $9 \mathrm{CS}$ & $\begin{array}{l}245,761 / \\
7,295\end{array}$ & Random & $\mathrm{RR}^{\mathrm{a}}$ & $\begin{array}{l}1.38 \\
(1.11 \\
1.73)\end{array}$ & $<0.01$ & $89 \%$ & 0.241 & No \\
\hline Zhang,2015[40] & $\begin{array}{l}\text { Gallstone disease } \\
\text { prevalence }\end{array}$ & $\begin{array}{l}2 \mathrm{CCS}, 6 \\
\mathrm{CS}\end{array}$ & $7,829 / 790$ & Fixed & OR & $\begin{array}{l}1.72 \\
(1.40, \\
2.12)\end{array}$ & 0.23 & $25 \%$ & 0.81 & No \\
\hline Del Pinto,2015[42] & $\begin{array}{l}\text { Vitamin D } \\
\text { deficiency } \\
\text { prevalence }\end{array}$ & $\begin{array}{l}9 \text { CCS,1 } \\
\text { CS, } 4 \\
\text { CSS }\end{array}$ & $1,891 / 625$ & Random & OR & $\begin{array}{l}1.64 \\
(1.30, \\
2.08)\end{array}$ & 0.37 & $7 \%$ & 0.11 & No \\
\hline Ning, 2019[44] & $\begin{array}{l}\text { Herpes zoster } \\
\text { infection risk (CD) } \\
\text { Herpes zoster } \\
\text { infection risk (UC) }\end{array}$ & $\begin{array}{l}7 \mathrm{CS} \\
6 \mathrm{CS}\end{array}$ & $\begin{array}{l}\mathrm{NR} / \mathrm{NR} \\
\mathrm{NR} / \mathrm{NR}\end{array}$ & $\begin{array}{l}\text { Random } \\
\text { Random }\end{array}$ & $\begin{array}{l}\mathrm{RR}^{\mathrm{a}} \\
\mathrm{RR}^{\mathrm{a}}\end{array}$ & $\begin{array}{l}1.74 \\
(1.57, \\
1.92) \\
1.40 \\
(1.31, \\
1.50)\end{array}$ & $\begin{array}{l}< \\
0.01 \\
0.00\end{array}$ & $\begin{array}{l}84 \% \\
72 \%\end{array}$ & $\begin{array}{l}0.33 \\
0.45\end{array}$ & $\begin{array}{l}\text { No } \\
\text { No }\end{array}$ \\
\hline
\end{tabular}

Abbreviation $\square \mathrm{CS}=$ cohort study; $\mathrm{CCS}=$ case-control study; $\mathrm{CSS}=$ cross-sectional study; $\mathrm{NR}=$ not report; RR=relative risk; OR=odds ratio; $\mathrm{SMR}=$ standardized mortality ratio ; $\mathrm{SIR}=$ standardized incidence ratio; $\mathrm{CD}=\mathrm{Crohn}$ 's disease; IBD=inflammatory bowel disease

$\mathrm{UC}=$ ulcerative colitis; No*=the original meta-analysis stated no evidence of publication bias; a=adjusted.

Table 2 Results of evidence quality for 29 outcomes classified by GRADE

\begin{tabular}{|c|c|c|c|}
\hline \multirow{2}{*}{$\begin{array}{l}\text { Level of } \\
\text { evidence }\end{array}$} & \multicolumn{3}{|l|}{ Outcomes } \\
\hline & Increased risk/ incidence/ prevalence of & No association with & $\begin{array}{l}\text { Decrease } \\
\text { risk of }\end{array}$ \\
\hline Moderate & $\begin{array}{l}\text { Thyroid cancer[29], Myocardial infarction[34], Preterm birth[36], Stillbirth[36], Gallstone } \\
\text { disease[40], Vitamin D deficiency[42]. }\end{array}$ & - & - \\
\hline Low & $\begin{array}{l}\text { Cervical cancer[27], Melanoma[31],Intrahepatic cholangiocarcinoma[30], Extrahepatic } \\
\text { cholangiocarcinoma[30], Coronary heart disease[34], Small for gestational age birth weight[36], } \\
\text { Rosacea[43]. }\end{array}$ & $\begin{array}{l}\text { Cardiovascular } \\
\text { disease mortality[35] }\end{array}$ & - \\
\hline Very low & $\begin{array}{l}\text { Prostate cancer[26], Colorectal cancer[28], Stroke[32], Ischemic heart disease[33], Cerebrovascular } \\
\text { disease[34], Venous thromboembolic [35], Congenital anomalies[36], Sexual dysfunction[37], } \\
\text { Parkinson's disease[ 38], Osteoporotic fracture[39],Herpes zoster infection (UC)[44], Herpes zoster } \\
\text { infection (CD)[44]. }\end{array}$ & $\begin{array}{l}\text { Arterial } \\
\text { thromboembolism[35] }\end{array}$ & - \\
\hline
\end{tabular}

Abbreviation $\square \mathrm{CD}=\mathrm{Crohn}$ 's disease; $\mathrm{UC}=$ ulcerative colitis.

\section{Figures}




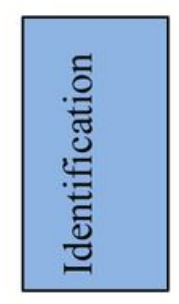
9310 articles identified through database screening:
-PubMed n=2372
-Embase $n=2489$
-Web of Science $n=2564$
-Cochrane library $n=872$
-VIP database $n=233$
-CIKN n=331
-Wanfang database $n=347$
-Hand searched $n=102$

8775 articles were excluded based on title review:

-Duplicates $n=4013$

$-I B D$ not exposure of interest $n=1195$

-Not meta-analyses/systematic reviews $n=1821$

- Disease not outcome of interest $n=1746$

535 articles reviewed by abstract screening
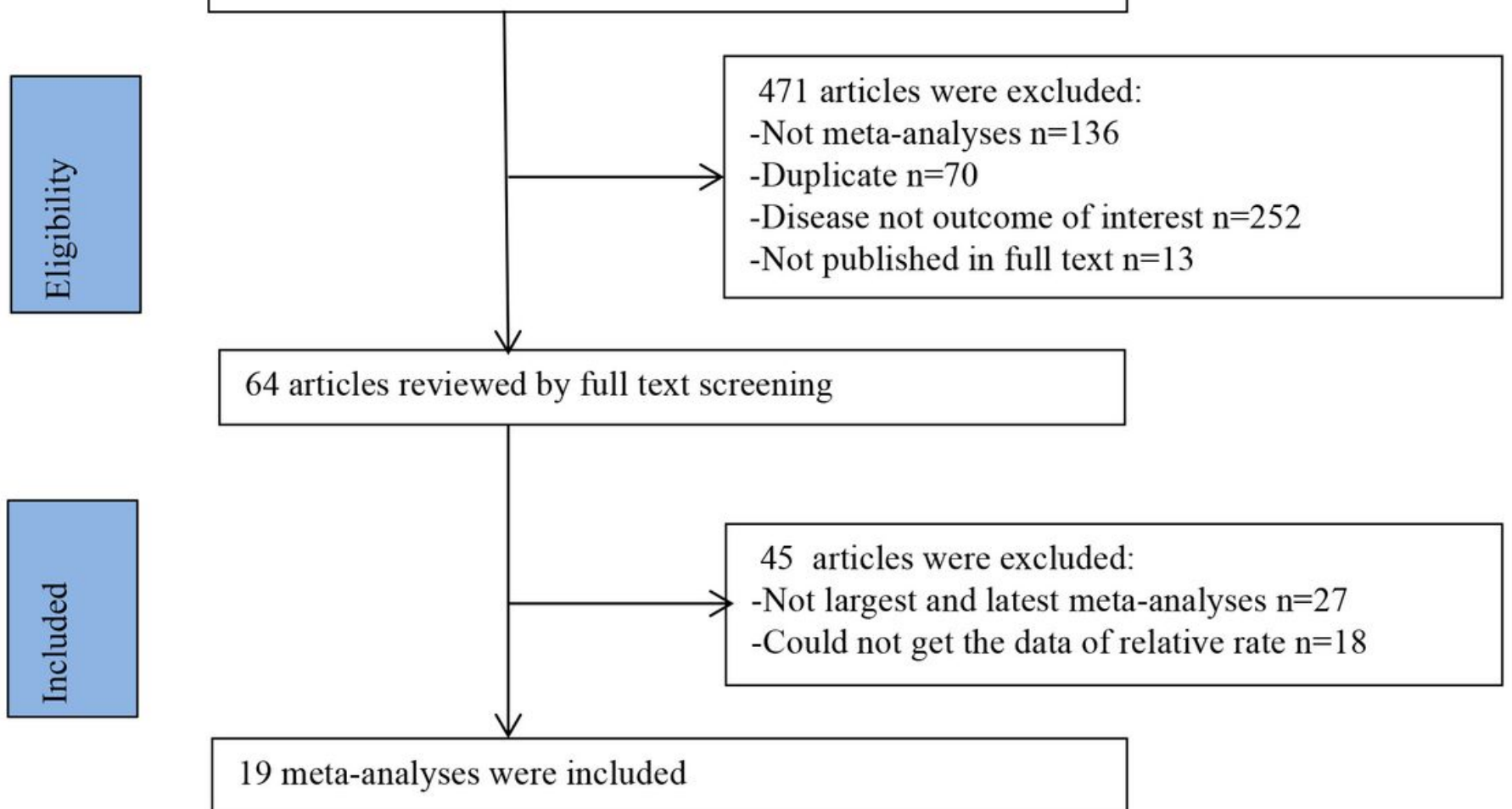

Fig.1 Flowchart of study selection process for umbrella review

\section{Figure 1}

Flowchart of study selection process for umbrella review 


\begin{tabular}{|c|c|c|c|c|c|c|}
\hline Association of IBD with & $\begin{array}{l}\text { No of } \\
\text { studies }\end{array}$ & Method & Effect size $(95 \% \mathrm{CI})$ & Effect size $(95 \% \mathrm{CI})$ & $\begin{array}{l}I^{2} \\
\text { (\%) }\end{array}$ & $\begin{array}{l}\text { Evidence for } \\
\text { publication } \\
\text { bias }\end{array}$ \\
\hline Prostate cancer risk [26] & 10 & Random & $H=-1$ & $\mathrm{OR}, 1.78(1.32,2.41)$ & 88 & No \\
\hline Cervical cancer risk [27] & 7 & Fixed & 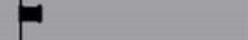 & $\operatorname{SIR}, 1.20(1.00,1.45)$ & 24 & No \\
\hline Colorectal cancer risk $[28]$ & 11 & Random & $\mathrm{H}-\mathrm{H}$ & $\operatorname{SIR}, 1.70(1.20,2.20)$ & 64 & No \\
\hline Thyroid cancer risk [29] & 8 & Fixed & in & OR, $1.75(1.48,2.07)$ & 15 & No \\
\hline Intrahepatic cholangiocarcinoma risk [30] & 5 & Random & $\longmapsto \longrightarrow$ & $\mathrm{OR}^{\mathrm{a}}, 2.61(1.72,3.95)$ & 73 & No \\
\hline Extrahepatic cholangiocarcinoma risk [30] & 3 & Random & $\mathbf{H}-\mathbf{H}$ & $\mathrm{OR}^{\mathrm{a}}, 1.47(1.10,1.97)$ & 22 & No \\
\hline Melanoma risk [31] & 12 & Random & in & $\mathrm{OR}^{\mathrm{a}}, 1.37(1.10,1.70)$ & 26 & No \\
\hline Stroke incidence [32] & 8 & Random & 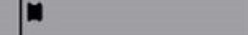 & $\mathrm{RR}^{\mathrm{a}}, 1.31(1.61,1.47)$ & 87 & No \\
\hline Ischemic heart disease risk [33] & 12 & Random & $\omega$ & $\mathrm{RR}^{\mathrm{a}}, 1.24(1.14,1.35)$ & 87 & No \\
\hline Cerebrovascular disease incidence [34] & 6 & Random & 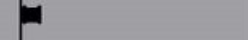 & $\mathrm{RR}, 1.25(1.08,1.44)$ & 91 & No \\
\hline Coronary heart disease incidence [34] & 6 & Random & 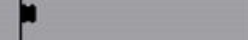 & RR, $1.17(1.07,1.27)$ & 83 & No \\
\hline Myocardial infarction incidence [34] & 4 & Fixed & 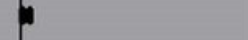 & $\mathrm{RR}, 1.12(1.05,1.21)$ & 0.0 & No \\
\hline Venous thromboembolic risk [35] & 10 & Random & 터 & RR, $1.96(1.67,2.30)$ & 99 & No \\
\hline Arterial thromboembolism risk [35] & 9 & Random & F & RR, $1.15(0.91,1.45)$ & 97 & No \\
\hline Cardiovascular disease mortality risk [35] & 15 & Random & 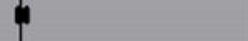 & SMR,1.03 $(0.93,1.14)$ & 70 & No \\
\hline Preterm birth incidence [36] & 23 & Random & 田 & OR, $1.85(1.67,2.05)$ & 31 & No \\
\hline SGA birth weight incidence $[36]$ & 13 & Random & a & OR, $1.36(1.16,1.60)$ & 56 & No \\
\hline Congenital anomalies incidence [36] & 11 & Random & $\mathbf{F i n}$ & OR, $1.29(1.05,1.58)$ & 46 & Yes \\
\hline Stillbirth incidence [36] & 10 & Random & -1 & OR, $1.57(1.03,2.38)$ & 30 & No \\
\hline Sexual function risk [37] & 8 & Random & F번 & RR, $1.56(1.28,1.89)$ & 80 & No \\
\hline Parkinson's disease risk [38] & 4 & Random & 四 & $\mathrm{RR}^{\mathrm{a}}, 1.41(1.19,1.66)$ & 83 & No \\
\hline Osteoporotic fractures risk [39] & 9 & Random & Im & $\mathrm{RR}^{\mathrm{a}}, 1.38(1.11,1.73)$ & 89 & No \\
\hline Gallstone disease prevalence $[40]$ & 8 & Fixed & FEH & OR, $1.72(1.40,2.12)$ & 25 & No \\
\hline Periodontitis prevalence [41] & 4 & Random & $\vdash$ & OR, $4.55(3.00,6.19)$ & 0.0 & No \\
\hline Vitamin D deficiency prevalence [42] & 14 & Random & $\mathbf{F H}$ & OR, $1.64(1.30,2.08)$ & 7 & No \\
\hline Rosacea risk [43] & 6 & Fixed & (1) & $\mathrm{RR}^{\mathrm{a}}, 1.66(1.50,1.84)$ & 48 & No \\
\hline \multirow[t]{2}{*}{ Herpes zoster infection risk [44] } & NR & NR & & NR & NR & NR \\
\hline & & & $\begin{array}{llllll}1 & 1 & 1 & 1 & 1 & 1 \\
1 & 2 & 3 & 4 & 5 & 6\end{array}$ & & & \\
\hline
\end{tabular}

Fig.2 Summary effect estimates with $95 \%$ confidence intervals from 28 meta-analyses of associations between IBD and risk of other diseases

Abbreviation: $\mathrm{IBD}=$ inflammatory bowel disease; $\mathrm{SGA}=$ small for gestational age; $\mathrm{NR}=$ not report; $\mathrm{RR}=$ relative risk; $\mathrm{OR}=\mathrm{odds}$ ratio; $\mathrm{SMR}=$ standardized mortality ratio; $\mathrm{SIR}=$ standardized incidence ratio; $\mathrm{a}=$ adjusted.

\section{Figure 2}

Summary effect estimates with $95 \%$ confidence intervals from 28 meta-analyses of associations between IBD and risk of other diseases 


\begin{tabular}{|c|c|c|c|c|c|}
\hline Sabgroup & $\begin{array}{l}\text { No of } \\
\text { stustios }\end{array}$ & Method & Effoct tive (95\%CD) & Entert tise $(95 \% \mathrm{CI})$ & $I^{2}(9 \%)(p)$ \\
\hline \multicolumn{6}{|l|}{ Associatioas of $\mathrm{VC}$ with } \\
\hline Prostate canser riks [26] & 4 & Random & $=-1$ & OR, 1.76 (1.06, 2.91) & $87,(0.0)$ \\
\hline Cenikal cancer risk [27] & 4 & Fixed & $m$ & SIR, $1.17(0.74,1.85)$ & $36,0.5)$ \\
\hline Colorestal cascer risk [28] & 8 & Random & $=1$ & SIR, $1.7(1.03,2.40)$ & 73.(NR) \\
\hline Thyoid canser rik; [29] & 3 & Fixed & $=$ & $\mathrm{OR}, 1.62(1.26,2.09)$ & $26,(0.25)$ \\
\hline Intrahequatic cholangiocarrioxema risk [30] & NR & $\mathrm{NR}$ & & $\mathrm{NR}$ & $\mathrm{NR}(\mathrm{NR})$ \\
\hline 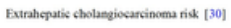 & NR & NR & & NR & NR.(NR) \\
\hline Melaneana ris [31] & , & Random & 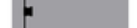 & $\mathrm{RR}^{\prime}, 1.23(1.01,1.50)$ & $0.0,(0.54)$ \\
\hline Stroke incisknes [32] & 6 & Random & $m$ & RR, 1.32(1.17, 1.50) & $\mathrm{NR},(0.0)$ \\
\hline 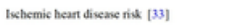 & 7 & Random & b & $\mathrm{RR}^{\prime}, 1.21(0.17,1.24)$ & $0.0,(0.73)$ \\
\hline Cerebronaswallar discas incidsnee [34] & 6 & Random & p & RR, $1.16(1.06,1.28)$ & $65,(0.01)$ \\
\hline Cosonary heart disease inxidence [34] & 5 & Random & p & $R R, 1.15(1.05,126)$ & $81,(0.9)$ \\
\hline Myocardsal infarction incidenese [34] & 3 & Fixed & p & $\mathrm{RR}, 1.13(1.02,1.26)$ & $0.0,(0.38)$ \\
\hline Vesous trambormbolic risk [35] & NR & NR & & NR & $\mathrm{NR},(\mathrm{NR})$ \\
\hline Anterial thromboembolism risk [35] & NR & $\mathrm{NR}$ & & $\mathrm{NR}$ & $\mathrm{NR},(\mathrm{NR})$ \\
\hline Cardiorascular disease mortality nisk [3S] & 12 & Random & - & $\operatorname{SMR}, 0.98(0.86,1.12)$ & $\mathrm{NR},(\mathrm{NR})$ \\
\hline Pretem birth incidenese [36] & 14 & Random & $m$ & or, $1.77(1.53,2.04)$ & $16,0.28)$ \\
\hline SGA birth weight issidenese [36] & $\mathrm{NR}$ & $\mathrm{NR}$ & & $\mathrm{NR}$ & $\mathrm{NR},(\mathrm{NR})$ \\
\hline Congenital anomalis incidence [36] & NR & NR & & $\mathrm{NR}$ & $\mathrm{NR},(\mathrm{NR})$ \\
\hline Salltinth inscidenace [36] & NR & NR & & NR & $\mathrm{NR},(\mathrm{NR})$ \\
\hline Sexual function nis [37] & NR & NR & & NR & $\mathrm{NR},(\mathrm{NR})$ \\
\hline Parkinson's dicease nisk [38] & 4 & Random & $m$ & $\mathrm{RR}^{\prime}, 1.30(1.15,1,17)$ & $0.0,(0.43)$ \\
\hline Oscopposotic fratures nisk [39] & NR & $\mathrm{NR}$ & & $\mathrm{NR}$ & $\mathrm{NR},(\mathrm{NR})$ \\
\hline Callstione diweane prevaknse [40] & 3 & Fised & + & OR, $1.12(0.75,1.68)$ & $0.0,(0.83)$ \\
\hline Periodomitis perzalence [41] & 3 & Random & $\longmapsto$ & OR, s.11 $(2.92,8.92)$ & $\mathrm{NR},(\mathrm{NR})$ \\
\hline Vitamin D seficicney prevalense [42] & , & Random & $\mapsto$ & OR, 2.28 (1.1.18,4.41) & 41,(0.21) \\
\hline Rowaces risk [43] & 4 & Randem & m & RRa $1.69(1.48,1.93)$ & $38,(0.2)$ \\
\hline Heppes zoster iffection risk [44] & 6 & Randem & $\left.\right|_{0123456789} ^{\mid}$ & $\mathrm{RR}^{2}, 1,1.40(1,31,1.50)$ & $72 .(0.0)$ \\
\hline
\end{tabular}

Fig. $3 \mathrm{~A}$ Summary effect estimates with $95 \%$ confidence of associations between type of IBD (UC) and risk of other diseases Abbreviation: UC- ulecrative colitis; SGA-small for gestational age, NR-not report, RR--relative risk; OR-odds ratio SMR-standardized mortality natio; SIR-standardized incidence ratio; a a adjusted.

\begin{tabular}{|c|c|c|c|c|c|}
\hline Subgroup & $\begin{array}{l}\text { No of } \\
\text { studies }\end{array}$ & Method & Effect size (95\%Cl) & Effect size $(95 \% \mathrm{Cl})$ & $I^{2}(\%),(p)$ \\
\hline \multicolumn{6}{|l|}{ Associations of $\mathrm{CD}$ with } \\
\hline Prostate cancer risk [26] & 4 & Random & m & OR, $1.29(1.04,1.61)$ & $88,(0.0)$ \\
\hline Cervical cancer risk [27] & 3 & Fixed & $1=-1$ & $\operatorname{SIR}, 1.63(1.13,2.35)$ & $0.0,(0.01)$ \\
\hline Colorectal eancer risk [28] & 3 & Random & -1 & SIR, $1.7(1.01,2.5)$ & $0.0,(\mathrm{NR})$ \\
\hline Thyroid cancer risk [29] & 6 & Fixed & $=-1$ & OR, $1.41(0.91,2.18)$ & $0.0,(0.65)$ \\
\hline Intrahkpatic cholangiocarcinoma risk [30] & $\mathrm{NR}$ & NR & & NR & $\mathrm{NR},(\mathrm{NR})$ \\
\hline Extrahcpatic cholangiocarcinoma risk [30] & $\mathrm{NR}$ & NR & & NR & $\mathrm{NR},(\mathrm{NR})$ \\
\hline Melanoma risk [31] & 7 & Random & $\mapsto$ & $\mathrm{RR}^{2}, 1.80(1.17,2.75)$ & $30,(0.19)$ \\
\hline Stroke incidence [32] & 6 & Random & $=$ & $\mathrm{RR}, 1.17(0.95,1.45)$ & $\mathrm{NR},(0,0)$ \\
\hline Ischemic heart disease risk [33] & 7 & Random & $=$ & $\mathrm{RR}^{2}, 1.24(1.04,1.48)$ & $90,(<0.001)$ \\
\hline Cerebrovascular disease incidenee [34] & 7 & Random & 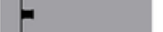 & $\mathrm{RR}, 1.27(1.07,1.51)$ & $85,(0.0)$ \\
\hline Coronary heart disease incidence [34] & 5 & Random & 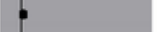 & $\mathrm{RR}, 1.08(1.03,1.12)$ & $0.0,(0.45)$ \\
\hline Myocardial infarction incidence [34] & 3 & Fixed & 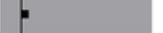 & RR, $1.14(1.03,1.26)$ & $0.0,(0.83)$ \\
\hline Venous thromboembolic risk [35] & NR & NR & & NR & $\mathrm{NR},(\mathrm{NR})$ \\
\hline Arterial thromboembolism risk [35] & $\mathrm{NR}$ & NR & & NR & $\mathrm{NR},(\mathrm{NR})$ \\
\hline Cardiovascular discase mortality risk [35] & 10 & Random & 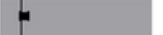 & SMR, $1.12(0.94,1.32)$ & $\mathrm{NR},(\mathrm{NR})$ \\
\hline Preterm birth incidence [36] & 14 & Random & $m$ & OR, $1.77(1.52,2.06)$ & $14,(0.3)$ \\
\hline SGA birth weight incidence [36] & $\mathrm{NR}$ & $\mathrm{NR}$ & & NR & $\mathrm{NR},(\mathrm{NR})$ \\
\hline Congenital anomalies incidence [36] & NR & NR & & NR & $\mathrm{NR},(\mathrm{NR})$ \\
\hline Stillbirth incidence [36] & NR & NR & & NR & $\mathrm{NR},(\mathrm{NR})$ \\
\hline Sexual function risk [37] & NR & $\mathrm{NR}$ & & NR & $\mathrm{NR},(\mathrm{NR})$ \\
\hline Parkinson's disease risk [38] & 4 & Random & $=$ & $\mathrm{RR}^{*}, 1.28(1.08,1.52)$ & $22,(0.28)$ \\
\hline Osteoporotic fractures risk [39] & NR & NR & & NR & $\mathrm{NR},(\mathrm{NR})$ \\
\hline Gallstone disease prevalence [40] & 3 & Fixed & $\omega$ & OR, 2.05 $(1.61,2.63)$ & $0.0,(0.54)$ \\
\hline Periodontitis prevalence [4I] & 4 & Random & $\longmapsto$ & OR, $3.96(2.39,6.54)$ & $\mathrm{NR},(\mathrm{NR})$ \\
\hline Vitamin D deficiency prevalence [42] & 12 & Random & $\ln$ & OR, $1.63(1.24,2.13)$ & $0.0,(0.7)$ \\
\hline Rosacea risk [43] & 4 & Random & $\longmapsto$ & $\mathrm{RR}^{2}, 2.08(1.26,3.46)$ & $68,(0.04)$ \\
\hline \multirow[t]{2}{*}{ Herpes zoster infection risk [44] } & 7 & Random & 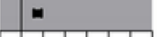 & $\mathrm{RR}^{2}, 1.74(1.57,1.92)$ & $84,(<0.01)$ \\
\hline & & & 1234567 & & \\
\hline
\end{tabular}

Fig.3B Summary effect estimates with $95 \%$ confidence of associations between type of IBD (CD) and risk of other diseases Abbreviation: $\mathrm{CD}=$-Crohn's Disease ulcerative; $\mathrm{SGA}=$-small for gestational age; $\mathrm{NR}=$ =not report; $\mathrm{RR}=$-relative risk; $\mathrm{OR}=$ odds ratio; SMR-standardized mortality ratio; SIR=-standardized incidence ratio; a-adjusted.

Figure 3

Fig.3A Summary effect estimates with $95 \%$ confidence of associations between type of IBD (UC) and risk of other diseases Fig.3B Summary effect estimates with $95 \%$ confidence of associations between type of IBD (CD) and risk of other diseases 


\begin{tabular}{|c|c|c|c|c|c|}
\hline $\begin{array}{l}\text { Associations of IBD with } \\
\text { (Stratified by gender) }\end{array}$ & $\begin{array}{l}\text { No of } \\
\text { studies }\end{array}$ & Method & Effect size $(95 \% \mathrm{CI})$ & Effect size $(95 \% \mathrm{CI})$ & $\mathrm{I}^{2}(\%),(\mathrm{P})$ \\
\hline \multicolumn{6}{|l|}{ Male } \\
\hline Colorectal cancer risk [28] & 3 & Random & $\longrightarrow$ & SIR, $1.90(0.80,3.0)$ & $84,(\mathrm{NR})$ \\
\hline Thyroid cancer risk [29] & 2 & Fixed & $\rightarrow \longrightarrow$ & OR, $2.05(1.38,3.05)$ & $\mathrm{NR},(0.26)$ \\
\hline Stroke incidence [32] & 5 & Random & $\mathbf{H}+\mathbf{H}$ & $\mathrm{RR}^{\mathrm{a}}, 1.23(1.04,1.45)$ & $72,(0.01)$ \\
\hline Ischemic heart disease risk [ 33$]$ & NR & Random & $\mathbf{H}$ & $\mathrm{RR}^{\mathrm{a}}, 1.19(1.03,1.38)$ & $\mathrm{NR},(0.0)$ \\
\hline Cerebrovascular disease incidence [34] & NR & Random & $1-1$ & $\mathrm{RR}, 1.34(1.11,1.61)$ & $\mathrm{NR},(\mathrm{NR})$ \\
\hline Coronary heart disease incidence [ 34$]$ & NR & Random & $n$ & $\mathrm{RR}, 1.13(1.09,1.17)$ & $\mathrm{NR},(\mathrm{NR})$ \\
\hline Sexual dysfunction risk [37] & 7 & Random & $\mapsto-1$ & RR, $1.41(1.09,1.81)$ & $80,(<0.001)$ \\
\hline Parkinson's disease risk [38] & 2 & Random & $\longmapsto$ & $\mathrm{RR}^{\mathrm{a}}, 1.53(1.09,2.15)$ & $\mathrm{NR},(\mathrm{NR})$ \\
\hline \multicolumn{6}{|l|}{ Female } \\
\hline Colorectal cancer risk [ 28] & 3 & Random & $\mapsto$ & $\operatorname{SIR}, 1.40(0.80,2.10)$ & $61,(\mathrm{NR})$ \\
\hline Thyroid cancer risk [ 29] & 2 & Fixed & $\longmapsto$ & OR, $1.48(1.11,1.97)$ & $\mathrm{NR},(0.79)$ \\
\hline Stroke incidence [32] & 5 & Random & $\mapsto$ & $\mathrm{RR}^{\mathrm{a}}, 1.46(1.12,1.91)$ & $90,(0.0)$ \\
\hline Ischemic heart disease risk [ 33] & NR & Random & HeH & $\mathrm{RR}^{\mathrm{a}}, 1.35(1.21,1.51)$ & $\mathrm{NR},(0.0)$ \\
\hline Cerebrovascular disease incidence [ 34$]$ & NR & Random & $\longmapsto$ & $\mathrm{RR}, 1.77(1.20,2.59)$ & $\mathrm{NR},(\mathrm{NR})$ \\
\hline Coronary heart disease incidence [ 34$]$ & NR & Random & Her & $\mathrm{RR}, 1.27(1.12,1.45)$ & $\mathrm{NR},(\mathrm{NR})$ \\
\hline Sexual dysfunction risk [37] & 5 & Random & $\longmapsto$ & $\mathrm{RR}, 1.76(1.28,2.42)$ & $70,(0.011)$ \\
\hline \multirow[t]{2}{*}{ Parkinson's disease risk [38] } & 2 & Random & $H$ & $\mathrm{RR}^{\mathrm{a}}, 1.49(1.29,1.72)$ & $\mathrm{NR},(\mathrm{NR})$ \\
\hline & & & $\begin{array}{l}1 \\
3\end{array}$ & & \\
\hline
\end{tabular}

Fig.4 Summary effect estimates with $95 \%$ confidence of associations between gender of IBD patients and risk of other diseases

Abbreviation: $\mathrm{NR}=$ not report; $\mathrm{RR}=$ relative risk; $\mathrm{OR}=\mathrm{odds}$ ratio; $\mathrm{SIR}=$ standardized incidence ratio; $\mathrm{a}=$ adjusted.

\section{Figure 4}

Summary effect estimates with $95 \%$ confidence of associations between gender of IBD patients and risk of other diseases 


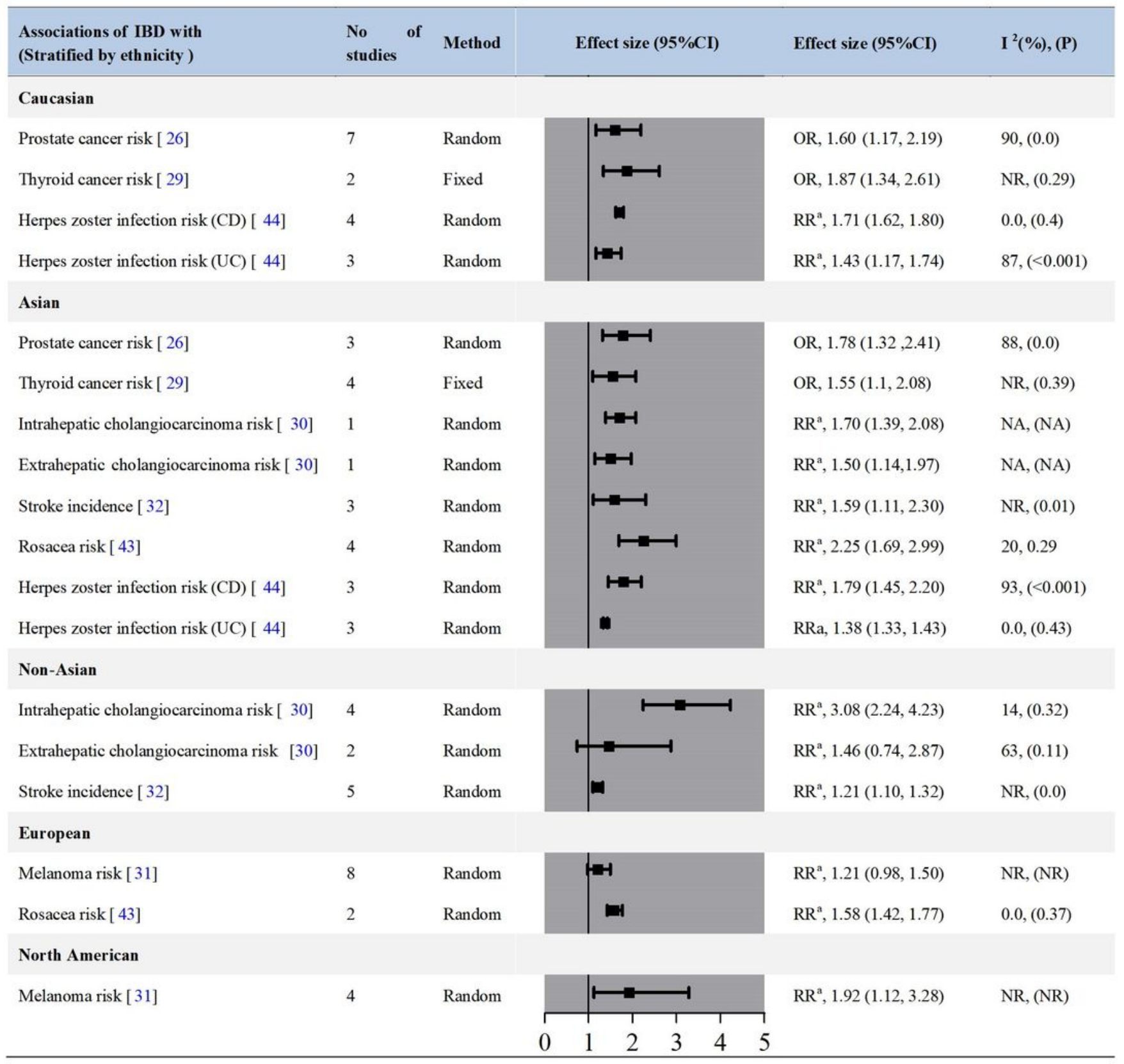

Fig.5 Summary effect estimates with $95 \%$ confidence of associations between ethnicity of IBD patients and risk of other diseases Abbreviation: $\mathrm{CD}=\mathrm{Crohn}$ 's Disease ulcerative; $\mathrm{UC}=$ ulcerative colitis; $\mathrm{NR}=$ not report; $\mathrm{RR}=$ relative risk; $\mathrm{OR}=\mathrm{odds}$ ratio; $\mathrm{a}=$ adjusted.

\section{Figure 5}

Summary effect estimates with $95 \%$ confidence of associations between ethnicity of IBD patients and risk of other diseases 


\section{Methodological quality of meta-analyses:}

high $(n=0)$, moderate $(n=1)$, low $(n=4)$, vey low $(n=14)$

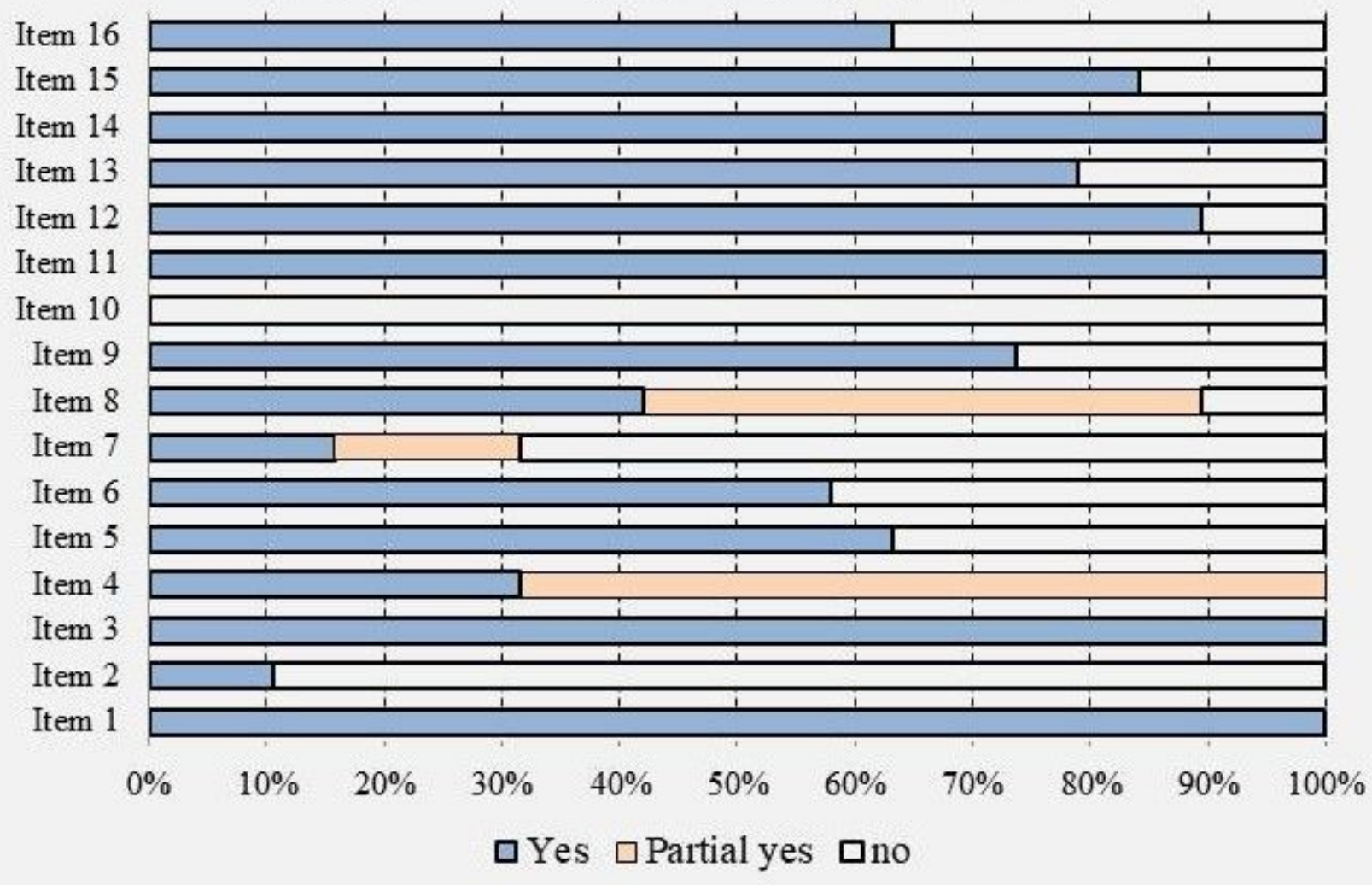

\section{Fig.6 Quality assessment of the included studies with AMSTAR}

The graph is showing a summary ( $\mathrm{n}=19$ meta-analyses) of the evaluation on each of the AMSTAR2 domains.

\section{Figure 6}

Quality assessment of the included studies with AMSTAR

\section{Supplementary Files}

This is a list of supplementary files associated with this preprint. Click to download.

- Appendix1.doc

- MOOSEChecklist.doc

- SupplementalTable14.docx 